\title{
XII.
}

\section{Ueber die Wirkungen des Fibrinfermentes im Organismus.}

\author{
Ein Beitrag zur Lehre \\ von der Thrombosis und vom Fieber. \\ (Aus dem physiologischen Institut zu Dorpat.) \\ Von \\ Max Edelberg, \\ stud. med.
}

Im Laufe des nun bald verflossenen Jahres hatte ich Gelegenheit auf der hiesigen chirurgischen Klinik einige Beobachtungen über den Verlauf des Wundfiebers unter der antiseptischen Behandlung zu machen. Ich war bald zu der Ueberzeugung gelangt, dass das Wundfieber auch jetzt noch denselben Charakter trägt, wie ihn uns bereits im Jahre 1861 Billroth beschrieben; stand dieses nun fest, so drängte sich unwillkürlich die Frage auf, welche von den in neuester Zeit zur Erklärung des Wundfiebers aufgestellten Hypothesen die meiste Wahrscheinlichkeit für sich hat. Ich unterzog somit die von verschiedenen Seiten ausgesprochenen Ansichten einer genaueren experimentellen Prifung; die Resultate waren negativ, so dass ich überzeugt bin, dass weder die unter dem Lister'schen Verbande gefundenen Bakterienvegetationen (Schüller), noch die Abkühlung oder Erkältung (Cred é), noch die Carbolsäure (K ï ster Sonnenburg) im Stande sind das auftretende Wundfieber zu erklären.

Es eriibrigte nun noch die Ansicht, dass das Wundfieber möglicherweise in Zusammenhang zu bringen sei mit dem in der Wunde angesammelten Blnte $\left(\mathrm{v} . \mathrm{W} \mathrm{ahl}^{1}\right)$ ) gleichfalls experimentell zu untersuchen; v. Wahl weist darauf hin, dass aus dem in der Wunde angesammelten Blute ein Körper resorbirt werden miisse, welchem das auftretende Wundfieber zuzuschreiben sei. Es handelte sich nun, falls diese Ansicht richtig war, darum, diesen Körper, der möglicher-

1) St. Petersburger med, Wochensehrift 1878 . No. 51. 
weise nichts anderes war, als das von A lexander Schmidt entdeckte Fibrinferment, zu finden.

Ich wandte mich daher nun an Hrn. Prof. Alexander Schmidt, unter dessen Leitung die nachfolgenden Versuche gemacht worden sind.

Bei dieser Gelegenheit halte ich es für eine angenehme Pflicht, meinem hochverehrten Lehrer meinen tiefgefühltesten Dank für die rege, unermüdliche Theilnahme, welche er meiner Arbeit zu Theil werden liess, auszusprechen.

Die Resultate dieser meiner zuletzt erwähnten Versuche erlaube ich mir hier mitzutheilen, weil sie meiner Ansicht nach ein allgemeines, pathologisches Interesse beanspruchen dürften, während die ersterwähnten Versuche von so rein chirurgischem Interesse siad, dass ich es richtiger halte, dieselben an einem anderen Orte zu veröffentlichen.

Indem ich nun auf diese Frage übergehe, muss ich daran erinnern, dass das Fibrinferment, wie von Alexander Schmidt ${ }^{1}$ ) gezeigt worden ist, im circulirenden Blute entweder gar nicht präexistirt, oder böchstens doch nur in verschwindend kleinen Spuren.

Vor Allem galt es daher festzustellen, ob durah Injection dieser Ferments in das Blut lebender Thiere nicht zunächst die specifische Wirkung desselben, d. h. Gerinnungen innerhalb des Gefässsystems, resp. bei grösserer Ausdehnung derselben nicht selbst plötzlicher Tod herbeigeführt werden könnte.

Armin $\mathrm{Köhler}{ }^{2}$ ) hat diesen Erfolg zwar erzielt, aber nur durch Injection von frischem, noch körperwarmem defibrinirtem Blate, zu welchem er griff, eben weil die Injection von reinen Fibrinfermentlösungen sich in seinen Versuchen sowohl, als in den früheren von Jakowicki ${ }^{3}$ ), als durchaus wirkungslos erwiesen hatte. ${ }^{4}$ ) Und doch erschien es durchaus nothwendig, durch Injection von reinen Fermentlösungen den Beweis zu liefern, dass Köhler's Resultate eben nur auf dem Fermentgehalt des frischen Blutes und auf nichts Anderem beruhen.

Die Annahme von Jakowicki, dass die Fermentinjection an

1) Die Lehre von den fermentativen Gerinnungserscheinungen in den eiweissartigen Körperflüssigkeiten. Dorpat $18 \pi 6$.

2) Ueber Thrombose und Transfusion u. s. w. Inaug.-Diss. Dorpat 1877.

3) Zur physiologischen Wirkung der Bluttransfusion. Inaug.-Diss. Dorpat 1875. S. $28-41$.

4) Ich benutze diese Gelegenheit, um im Auftrage des Hrn. Prof. Alexander S chmidt zu erklären, dass er der Arbeit des leider verstorbenen Armin Köhler durchaus fremd ist. 
sich „nicht gefährlich“ sei, erscheint aber um so mehr verfrïht, als er durch seine eigenen Versuche eine wichtige Thatsache festgestellt hat, welche es einerseits erklärlich macht, warum seine Injectionen von Fibrinferment keine verderblichen Wirkungen hatten, und welche andererseits auf den Weg hinweist, auf welchem eine solche Wirkung zu erzielen wäre. Jakowicki fand nämlich, dass das in das Venensystem von Katzen injicirte Fibrinferment durch den Organismus zwar wieder eliminirt wurde, aber nur sehr allmählich, so dass selbst nach 24 Stunden noch Spuren desselben im Blute des Versuchsthieres nachweisbar waren. Dabei muss noch besonders hervorgehoben werden, dass die von ihm injicirten Fermentmengen, wie durch einen besonderen Vorversuch festgestellt wurde, hingereicht hätten, um etwa $300-360$ C.-Ctm. mit schwefelsaurer Magnesia gemischten Pferdeblutes in einer Viertelstunde zur Gerinnung zu bringen, während die Gesammtmenge des Blutes der von ihm zu den Injectionsversuchen benutzten Katzen (zu $1 / 13$ des Körpergewiehtes angenommen) etwa nur 180 C.-Ctm. betragen haben mochte.

Diese Ergebnisse führen aber zu nachfolgenden beiden bereits früher von Al. Schmidt ${ }^{1}$ ) betonten und für meine vorliegende Arbeit äusserst wichtigen Sätzen:

1. Der Organismus besitzt die Fähigkeit sich des Fibrinferments entweder durch Zerstörung oder durch Ausscheidung zu entledigen.

2. Der Organismus disponirt über Kräfte, durch welche er dem Fibrinferment, so lange dasselbe sich im Blute befindet, Widerstand zu leisten im Stande ist, seine Wirkung zu paralysiren vermag.

. Stellt man sich nun weiter vor, dass im circulirenden Blute gewissermaassen ein labiles Gleichgewicht herrscht und damit eine beständige Tendenz zur Gerinnung gegeben ist, so wird man weiter zur Annahme gefuhrt, dass behufs Beseitigung der Gefahr die im Organismus enthaltenen, die Wirkung des Fibrinferments paralysirenden Widerstände sehr grosse sein könnten, mindestens zu grosse in Relation zur Wirksamkeit der von Jakowicki zu seinen Injectionsversucheu benutzten Fermentlösungen. Es erscheint denkbar, dass die Injection „nicht gefährlich“ war, weil der Organismus das injicirte Fibrinferment zunächst lahm zu legen vermochte, um es dann ganz za eliminiren. Man wird sich weiter vorstellen dürfen, dass diese Gegenarbeit des Organismus nach Bedürfniss einer beträchtlichen Steigerung fähig ist, aber ebenso auch, dass es einen

1) Pflüger's Archiv. Bd. XI. S. 333.

Archiv für experiment. Pathológie u. Pharmakologie. XII. Bd. 
Grad der Wirksamkeit der injicirten Fermentlösungen geben kann, bei welchem alle Widerstände im Organismus mit einem Schlage niedergeworfen werden und somit die verderbliche Wirkung eintritt.

Dafür, dass die zu injicirende Fermentlösung einen solchen Grad von Wirksamkeit besitzt, kann der Versuch im Reagensglase absolut keinen Maassstab abgeben, weil hier jene, vom Organismus ausgehenden Gegenwirkungen durchaus fehlen. Extrahirt man z. B. 1 Grm. durch Alkohol coagulirtes und pulverisirtes Serumalbumin mit 80 bis 100 C. - Ctm. Wasser, so wird man sich leicht davon überzengen können, dass das wässrige Extract passende Gerinnungsmischungen, z. B. verdünntes Salzplasma (worïber ich das Nähere unten angeben werde) in einigen Secunden, ja zuweilen fast momentan zur Gerinnung bringt; daraus darf man aber offenbar nicht auf einen annähernd ähnlichen Effect der Fermentlösung auf das Blut im Organismus schliessen, vielmehr ist es denkbar, dass sie dort nicht schädlicher als Wasser wirkt. Eine zehnmal concentrirtere Fermentlösung: dagegen wiirde im Reagensglase kaum wirksamer erscheinen als die verdünnte, im Organismus aber möglicherweise verderbenbringend sein.

Hierbei ist ferner zu berücksichtigen, dass die bisher übliche Darstellung des Fibrinferments durch Fällen von Blutserum mit Alkohol, längeres Stehenlassen unter Alkohol (behufs möglichst vollkommener Coagulirung des Albumins), Trocknen des Coagulums und Extrahiren mit Wasser mehrere Uebelstände mit sich bringt, welche die Gewinnung sehr concentrirter, wirksamer Fermentlösungen erschweren. Diese Uebelstände sind:

1. Das reine Serum kann nur durch die spontane Scheidung vom Blutkuchen gewonnen werden, was wenigstens $1-2$ Tage Zeit beansprucht, unterdessen vermindert sich aber der Fermentgehalt der Blutflissigkeit, wie Al. Schmidt und Köhler gezeigt haben, sehr beträchtlich, wenn er auch gross genug bleibt zur Anstellung von kiunstlichen Gerinnungsversuchen-im Reagensglase.

2. Der Alkohol selbst schwächt das Fibrinferment allmählich, wenn auch sehr langsam ab.

3. Beim Extrahiren mit Wasser gewinnt man immer nur einen Bruchtheil des vom Coagulum eingeschlossenen Ferments.

Unter Berïcksichtigung der von Jakowicki nachgewiesenen Gegenwirkungen des Organismus wăre es demnach einerseits verständlich, wenn die Injection von Fibrinfermentlösungen resultatlos bliebe, trotzdem, dass durch Injection von frisehem körperwarmem Blute ausgedehnte Thrombosen bewirkt werden, andererseits erschien 
es aber doch lockend zu versuchen, ob die ersteren sich nicht ebenso wirksam gestalten liessen, wie das frische Blut.

Da mir keine andere Methode der Fermentdarstellung zu Gebote stand, als die oben erwähnte, so konnte ich die mit ihr verknüpften Uebelstände auch nur dadurch auszugleichen versuchen, dass ich den Alkohol kürzere Zeit auf das Coagulum einwirken liess (etwa 8-10 Tage), dass ich dasselbe ferner mit wenig Wasser (ein Theil zerriebenes Coagulum und acht Theile Wasser) extrahirte. Jak owicki und Köhler haben viel grössere Wassermengen zur Extraction benutzt und extrahirten nur kurze Zeit (wenige Minuten), indem sie sich auf die ursprünglichen nur in Hinblick auf künstliche Gerinnungsversuche gemachten Angaben von Al. S chmidt stiitzten. Auch hierin wich ich von den Genannten ab, indem ich das Wasser längere Zeit (etwa 1-2 Stunden) auf das Pulver einwirken liess, bevor ich filtrirte. Was die ersterwähnte Abweichung von der bisherigen Methode der Fermentdarstellung anbetrifft, nämlich die kürzere Zeit dauernde Einwirkung des Alkohols auf das Coagulum, so ging ich von der Annahme aus, dass es für die von mir erwartete specifische Wirkung meiner Wasserextracte auf das circulirende Blut ohne Belang sei, ob sie mit etwas mehr oder weniger Eiweiss verunreinigt sind.

Ich muss nun aber noch hervorheben, dass durch diese Art der Darstellung die Fermentlösungen wegen des grossen Verbrauches an Substanz, deren Gewinnung viel Alkohol erfordert, sehr theuer werden, besonders da das pulverisirte Coagulum im Wasser stark aufquillt und beim Filtriren etwa die Hälfte desselben zurïckhält; das Auspressen ist hierbei nicht anwendbar, da das gequollene Pulver jede Leinewand durchdringt. Demnach musste ich jedesmal, wenn ich eine gewisse Menge Lösung erhalten wollte das Doppelte von derjenigen Menge Pulver und Wasser nehmen, welche nach der Rechnung erforderlich war.

In vielen Fällen habe ich nicht Serum, sondern frisches ausgepresstes Blut zur Darstellung des Fibrinferments benutzt. Dasselbe wurde gleichfalls mit $10-15 \mathrm{Vol}$. Alkohol gefällt; in Betreff des Niederschlages aber wurde bedacht, dass er zum grösseren Theil aus dem, in Bezug auf das Fibrinferment, ganz indifferenten Rückstande der rothen Blutkörperchen bestand, weshalb er nicht mit acht, sondern nur mit vier Theilen Wasser extrahirt wurde; auch hier ging nur etwa die Hälfte durchs Filtrum, aber die Masse quoll weniger stark auf und es liess sich deshalb durch Auspressen durch Leinewand stets noch etwas Flüssigkeit gewinnen, welche einer 
zweiten Filtration unterworfen werden konnte. Diese Lösungen waren mehr weniger roth von etwas beigemengtem Hämatin.

Alle meine Fermentlösungen wurden aus Rinderblutserum, resp. aus frischem, ausgepresstem noch körperwarmem Rinderblute dargestellt. Ich werde im Nachfolgenden die ersteren, die entweder. farblos oder von mitaufgenommenem Serumfarbstoff schwach gelblich gefärbt waren als Lösungen $A$ bezeichnen und die letzteren, mehr weniger rothgefärbten, als Lösungen $B$. Die pulverisirte Substanz, durch deren Extraction mit Wasser ich die Fermentlösungen gewann, werde ich der Kürze halber als weisses und rothes Fermentpulver bezeichnen.

Behufs Ermittelung der Zusammensetzung analysirte ich einmal ein gemessenes Volum der farblosen durch Extrahiren mit Wasser (acht Theile) gewonnenen Fermentlösung durch Trocknen, Wägung des Gesammtruickstandes, Verkohlen desselben, Ausziehen der Kohle mit kochendem Wasser, Trocknen des Wasserextracts, Veraschen der nachbleibenden Kohle und Wägung beider Rückstände. Ich fand in 100 C. - Ctm. der Fermentlösung 2,314 Grm. Eiweiss (gewöhnliches Albumin mit Spuren von Paraglobulin) 0,137 Grm. löslicher Salze und 0,015 Grm. Erdphosphate. Die löslichen Salze bestanden iiberwiegend aus Chloriden und ausserdem aus schwefelsauren, phosphorsauren und kohlensauren Alkalien. In einer rothen, durch Extrahiren des entsprechenden Fermentpulvers mit vier Theilen Wasser gewonnenen Fermentlösung wurde nur der Gesammtrückstand durch Trocknen und Wägen bestimmt. Derselbe betrug in 100 C.-Ctm. 1,132 Grm.

Auffallend ist der hohe Gehalt der farblosen Fermentlösung an Eiweiss, den Al. Schmidt und Jakowicki weit unter 1 pCt. gefunden haben. Zur Erklärung genügt, dass die Letzteren den Alkohol monatelang auf das Coagulum einwirken liessen, eben um die Wiederauflöslichkeit des Eiweisses möglichst zu beseitigen und dass sie das Fermentpulver mit viel grösseren Wassermengen und zugleich viel kürzere Zeit extrahirten. Eigenthümlich aber ist, dass die aus dem ausgepressten Blute dargestellte Fermentlösung beträchtlich weniger feste Stoffe enthielt, als die aus Serum gewonnene. Eine später anzuführende Analyse einer rothen Lösung ergab einen noch kleineren Gehalt an festen Stoffen, als hier angegeben worden. Da die Darstellungsmethode der rothen Lösungen stets dieselbe war, wie die der farblosen, so bliebe zur Erklärung vielleicht die Annahme iibrig, dass das durch Alkohol zersetzte und coagulirte Hämoglobin eine schwerer lösliche Masse darstellt, welche das leichter lösliche Serumalbumin einschliesst. 
Um die fermentative Wirksamkeit meiner Lösungen zu prüfen, bediente ich mich einer das Gerinnungssubstrat enthaltenden, aber fermentfreien Fltissigkeit, die man sich folgendermaassen bereitet:

Pferdeblut wird direct aus der Vene in einer 25 proc. Lösung von schwefelsaurer Magnesia (drei Theile Blut auf ein Theil Salzlösung) aufgefangen, die Senkung der Blutkörperchen abgewartet (wozu gewöhnlich 24 Stundén erforderlich sind), das Plasma abgehoben, im Vacuum über Schwefelsäure rasch getrocknet und der Rückstand pulverisirt. Löst man ein Gewichtstheil dieses Pulvers in sieben Theilen Wasser, was in einigen Stunden von Statten geht, so erbält man eine salzhaltige Flüssigkeit, welche ziemlich genau denselben Wassergehalt besitzt, wie das ursprüngliche mit der Salzlösung gemischte Plasma und zugleich keine Spur von Fibrinferment enthält, was schon von Al. Schmidt ${ }^{1}$ ) nachgewiesen ist.

Ich werde diese Flüssigkeit im Nachstehenden als "S al zp la sma“ oder als "Reactionsfluissigkeit" bezeichnen. Wegen des grossen Salzgehaltes gerinnt diese Flüssigkeit auch bei Fermentzusatz nicht; je mehr man aber durch Verdïnnen mit Wasser den relativen Salzgehalt herabdrückt, desto leichter und schneller gerinnt sie bei Fermentzusatz. Bei Verdünnung mit dem achtfachen Volum Wasser reichen schon kleine Mengen von Fibrinferment hin, um eine meist in wenigen Minuten ablaufende Gerinnung hervorzurufen. Dagegen bleibt das mit acht Theilen reinen Wassers verdünte "Salzplasma" unbegrenzt lange flüssig. Um stets unter gleichen Bedingungen zu arbeiten, mass ich die Flüssigkeiten so ab, dass immer das zugesetzte Wasser mit der zugesetzten Fermentlösung zusammen das achtfache Volum des „Salzplasma“ betrugen. Meine gewöhnliche Mischung war: ein Theil „Salzplasma", sieben Theile Wasser und ein Theil der Fermentlösung. Nur bei sehr schwach wirkenden Fermentlösungen habe ich dieses Verhältniss geändert, indem ich mehr von denselben und dafür weniger Wasser in die Mischung brachte.

Bekanntlich kann man auch das von den Blutkörperchen abgehobene "Salzplasna" ohne weiteres als Reactionsflüssigkeit gegen das Fibrinferment benutzen. Aber unter diesen Verhältnissen gerinnt die Fliissigkeit auch schon nach blossem Verdünnen mit Wasser (wie bereits van Al. Schmidt und Jak owicki angegeben worden), wenn auch sehr unbedeutend und nach Verlauf mehrerer Stunden. Dieses erklärt sich aus der bekannten Thatsache, dass die schwefelsaure Magnesia die Entstehung des Fibrinferments nicht absolut hindert.

1) Vgl. 2. S. 22 und 23. 
Man bedenke, dass man das "Salzplasma" meist erst 24 Stunden nach der Mischung des Blutes mit der Salzlösung zum Versuch gewinnen kann, während dieser Zeit entwickeln sich immerhin Spuren von Fibrinferment, welche alsdann nach geschehener Verdiunnung des „Salzplasma“ mit Wasser zur Wirkung kommen. Trocknet man dagegen das "Salzplasma" im Vacuum und löst den Riuckstand in Wasser wieder auf, so ist das „Salzplasma“ nun absolut fermentfrei und deshalb unter allen Umständen als Reactionsflitssigkeit vorzüglich brauchbar. Die Erklärung hierfür liegt in folgender mir von Herrn Prof. Al. Schmidt mitgetheilten und noch nicht veröffentlichten Thatsache. Verdunstet man eine Fibrinfermentlösung im Vacuum über Schwefelsäure, so findet man, dass ihre Wirksamkeit mit der Concentration nicht zunimmt, sondern anfangs sich gleich bleibt und zuletzt sogar abnimmt; löst man nach völligem Eintrocknen den Rïckstand in Wasser wieder auf, so erhält man eine gänzlich unwirksame Lösung; durch das Trocknen im Vacuum wird also das Fibrinferment zerstört. Die Anwendung auf das geringe Mengen von Ferment enthaltende und im Vacuum getrocknete "Salzplasma" ergibt sich von selbst.

Aus den einleitenden Bemerkungen lässt sich entnehmen, welchen Weg ich einschlagen musste, um zu Resultaten kommen zu können.

Ich gebrauchte zu meinen Experimenten Hunde, Katzen, Kaninchen und Frösche.

In Betreff der Temperaturmessungen an den Thieren und in Bezug anf die normalen Temperaturen der Hunde muss ich Folgendes bemerken. - Ich war stets bemüht, die Thiere so wenig wie möglich aus ihren normalen Verhältnissen zu bringen; zu dem Zwecke wurden die Messungen, und zwar immer im Rectum, derartig angestellt, dass die Hunde stets frei standen und ihnen nur der Kopf gehalten wurde; bei der Leichtigkeit, mit welcher sich die Hunde an die Temperaturmessungen gewöhnen, hat dieselbe bei ihnen keine Schwierigkeit. Ferner wurde nach Möglichkeit dafür Sorge getragen, dass die Thiere einige Zeit vor der Temperaturmessung ihr Rectum entleerten; sie wurden zu diesem Zwecke hinausgebracht und dann erst, nachdem Defäcation erfolgt war und die Thiere sich wieder einige Zeit hindureh ruhig im Zimmer verhalten hatten, wurden die Messungen vorgenommen und die Experimente begonnen.

Bei Katzen war die Sache schon schwieriger, dieselben mussten aus Riicksicht auf ihre Krallen in einem Sacke gehalten werden. Zu den Temperaturmessungen gebrauchte ich in $1 / 10{ }^{0}$ getheilte Thermo- 
meter nach Celsius, welche, sehr oft controlirt, selten grössere Differenzen als in der zweiten Decimale mit einem Normalthermometer zeigten.

Jedes Versuchsthier wurde immer mit demselben Thermometer gemessen und wurde dasselbe stets gleich weit ins Rectum eingeführt, etwa $10-12 \mathrm{Ctm}$. War es einmal eingeführt, so wurde es fixirt und blieb unverrückt so lange liegen, bis die Quecksilbersäule nicht mehr über die einmal erreichte Höhe hinaus stieg, dieser Modus wurde bei Hunden eingehalten. Bei Katzen verfuhr ich aber anders. Da dieselben in etwas gezwungener Stellung gehalten werden mussten und bekanntlich bei Thieren als Folge einer mehr weniger gezwungenen Stellung sehr bald ein Sinken der Temperatur sich ibemerklich macht, so liess ich das Thermometer so lange liegen, bis die Quecksilbersäule allmählich von der einmal erreichten Höhe abzufallen begann, darauf notirte ich den höchsten Stand.

Ueber die normalen Rectumtemperaturen der Hunde findet sich Folgendes in der zugänglichen Literatur. Billroth ${ }^{1}$ ) sagt: „Nach Messungen an 32 gesunden Hunden (es gehen die Zahlenangaben voran) schwankt die Rectumtemperatur zwischen $38,2^{\circ}$ und $40,15^{\circ} \mathrm{C}$.; die Differenz beträgt also $2{ }^{0}$ C." Nach Siedamgrotzky ${ }^{2}$ ) sind Hunde bedeutenden Temperaturschwankungen ausgesetzt. Bei 190 Messungen an 17 Hunden fand er $38,3^{\circ} \mathrm{C}$. als Normaltemperatur (Flemming $38,5^{\circ}$ C., Krabbe $38,7^{\circ}$ C.). Die abendliche Steigerung beträgt meist $0,2^{0} \mathrm{C}$. Am meisten wirkt auf die Hunde die Aussentemperatur ein, aber in sehr verschiedener Weise auf die einzelnen Individuen. Während bei einigen nach einstiundigem Liegen an der Sonne bei $40^{\circ} \mathrm{C}$. eine Temperatursteigerung von 1,8 ${ }^{\circ} \mathrm{C}$. eintrat, erfolgte bei anderen nur eine solche von $0,4^{\circ} \mathrm{C}$.

Als Applicationsmethode wählte ich für die folgenden Versuchsreihen die directe Injection ins Blut, weil ich diese Methode für die rationellste halte, denn wenn z. B. auf solche Weise Gerinnungen hervorgerufen wurden, so war das ja nur ein erwünschter Effeet, traten aber keine Gerinnungen ein, so konnten doch etwaige andere Effecte der Fermentinjection genauer studirt werden, weil die Versuche von gewissen Complicationen freiblieben, wie ich sogleich zeigen werde.

1) Beobachtungsstudien über Wundfieber und accidentelle Wundkrankheiten. Langenbeck's Archiv. Bd. XIII. S. 601.

2) Bericht über das Veterinärwesen in Sachsen für das Jahr 1873. Herausgegeben von G. C. Heubner. Ref. in der Deutschen Zeitschrift für Thiermedicin und vgl. Pathologie von Bollinger und Frank 187 . 
Als Injectionsstelle wählte ich, mit Ausnahme weniger Fälle, wo die Carotis gebraucht wurde, die Jugularis externa und zwar aus dem Grunde, weil ich dadurch den Thieren die Möglichkeit nahm, ihre Wunden zu belecken, die Verbände za verschieben und den Heilungsprocess dadurch zu beeinflussen. Ich habe nämlich in allen Fällen unter Thymolspray operirt und nachher einen antiseptischen Verband mit Salicylwatte und Carbolzeug angelegt, so dass fast alle Wunden, ohne auch nur einen Tropfen Eiter zu liefern, per primam intentionem heilten, weshalb ich denn auch oben den Ausspruch thun konnte, meine Versuche seien frei von Complicationen von Seiten der Wunden geblieben. Selbst von den Katzen starb mir nachträglich keine an den Folgen der Operation. Ich habe in den meisten Fällen schon am zweiten Tage nach der Operation beim Verbandwechsel die Wunde geschlossen gefunden, freilich hatte ich zu allen Ligaturen und Nähten Catgut gebraucht, so dass eine Abstossung derselben natiurlich nicht eintreten konnte.

Die Injectionsfliissigkeiten wurden stets auf $30-32^{\circ} \mathrm{C}$. erwärmt.

Es lag mir nun ob, durch das Experiment zu ermitteln, ob man im Stande sei durch Injection von reinen Fermentlösungen die im Organismus vorhandenen Widerstände so momentan lahm zu legen, dass durch ausgedehnte Thrombose plötzlicher Tod eintrat; war dieses der Fall, so ergab sich von selbst die weitere Folgerung, dass ein Stoff, der in hinreichender Menge in den Organismus gebracht tödtlich wirkt, in kleineren, nicht tödtlichen Mengen offenbar nicht indifferent gegen den Körper sich verhalten könne. Demnach musste versucht werden zu ermitteln, ob in solchen Fällen geringerer nicht tödtlicher Wirkung des Ferments der Ausdruck der Reaction des Organismus gegen diese Schädlichkeit sich nicht vielleicht speciell dadurch documentirt, dass ein gewisser Symptomencomplex zur Beobachtung kommt, dessen wichtigstes Moment eine bedeutende Temperatursteigerung ist. Jakowicki und Köhler leugnen dieses zwar und Köhler sagt dartiber (a. a. O.S. 7): „ . . . . ebensowenig wird die Körpertemperatur alterirt, die namentlich nie Fieberhöhe aufweist. Das Fibrinferment ist also kein fiebererregender Stoff." Die Gründe, weshalb Jakowicki und Köhler zu solchen Resultaten gekommen sind, habe ich bereits mehrfach erwähnt. In den folgenden Versuchen glaube ich nun den sichern Beweis dafür zu liefern, dass sowohl Jak owicki's als Köhler's Angaben sich aus der geringen Wirksamkeit der von ihnen benutzten Fermentlösungen erklären. 
Die Versuche selbst sind ohne Riicksicht auf das Datum, nur ihrer sachlichen Zusammengehörigkeit nach geordnet; sie zerfallen in :

I. solche, in welchen durch momentane Gerinnungen der Tod hervorgerufen wurde;

II. solche, in welchen zwar nicht der Tod, aber immer ein charakteristischer mit Temperaturerhöhung verbundener Symptomencomplex zur Beobachtung kam;

III. solche, in welchen Controlversuche angestellt wurden.

Der Kürze halber werde ich diese Versuchsreihen als Reihe I, II, III von einander unterscheiden.

\section{Reibe I.}

Versuch 1. Am 26/VI. 79. injieirte ich einer Katze von $2180 \mathrm{Grm}$. 24 C.-Ctm. der Lösung $A$ in die linke Vena jugularis. Während der sehr langsamen Injection wird das Thier sehr unruhig, bekommt eine sehr starke Dyspnoe und stirbt noch vor Beendigung der Injection. Die sofort bei noch pulsirendem Herzen angestellte Section ergibt folgenden Befund: Das rechte Herz ist ad maximum dilatirt, beim Einschneiden in dasselbe fliesst etwas dunkles flüssiges Blut ab, im übrigen ist es aber vollgepfropft von festen, verfilzten Gerinnseln; denselben Befund bietet auch der Vorhof dar. Diese Gerinsel lassen sich hinein verfolgen bis in die feinsten Verzweigungen der Arteria pulmonalis; auch in den Lungenvenen sind feste Gerinnsel, ebenso in den grösseren Venenstämmen der Unterleibshöhle. In den Lebervenen sind keine Gerinnsel, aber sie sind ebenso wie die übrigen Venen, welche keine Gerinnsel enthalten, strotzend mit Blut erfüllt. Das linke Herz ist stark contrahirt und leer. Das noch flüssige Blut ist dunkel und gerinnt schwer. Sonst ist an dem Thiere nichts Abnormes zu constatiren.

Versuch 2. Einem Kater von 3310 Grm. wurden am 27/VI. 79. 54 C.-Ctm. der Lös ung A in die rechte Vena jugularis injicirt. Etwa 2 Minuten nach der Injection tritt plötzlich sehr heftige Dyspnoe auf und unter allen Zeichen der Asphyxie geht das Thier nach ein paar Augenblicken zu Grunde. Die sofort angestellte Section ergibt dieselben Befunde wie der Versuch 1.

Versuch 3. Am 4/VII. 79. wurden einer Katze von 3350 Grm. 50 C.-Ctm. der Lösung A in die linke Vena jugularis injicirt. Die Injection dauerte 10 Minuten, das Thier wird während derselben sehr unruhig, bekommt eine äusserst heftige Dyspnoe, das Herz beginnt sehr heftig zu schlagen und mit Beendigung der Injection ist auch das Thier todt. Die Section ergibt dieselben Befunde wie die der Versuche 1 und 2.

Versuche 4, 5, 6, 7. Vier Katzen von je 2100, 1980, 2150, 2220 Grm. Körpergewicht injicirte ich im Laufe des Decembers 1879 je 40, 20, 20, 20 C.-Ctm. und zwar in den drei ersten Fällen der Lösung B, im letzten aber der Lösung $A$. In allen vier Fällen trat unmittelbar nach der Injection der asphyktische Tod ein und ergab die Section, welche bei 
noch pulsirendem Herzen vorgenommen wurde, im rechten Ventrikel und Vorhofe derbe in den Trabekeln verfilzte Gerinnsel bei blutleerem, contrahirtem linkem Herzen; die Pulmonalis bis in die feinsten Verzweigungen hinein von Gerinnseln verstopft.

Dass man aber nicht immer so eclatante Resultate erzielt, wie in diesen sieben Versuchen, dafür sprechen die nun folgenden zwei Versuche:

Versuch 8. Am 1/VII. 79. injicirte ich einer Katze von $2560 \mathrm{Grm}$. 50 C. - Ctm. der $\mathrm{L}$ ösung $\mathrm{A}$ in die rechte Jugularis. Das Thier bekam eine äusserst heftige Dyspnoe und es schien, als ob es dem Tode sehr nahe sei, trotzdem erholte es sich und wurde nach etwa 10 Minuten getödtet; der Sectionsbefund war aber ein negativer.

Versuch 9. Einer Katze von $2800 \mathrm{Grm}$, einem äusserst kräftigen und wilden Thiere, wurden am 3/VII. 79. hintereinander in beide Vv. jugular. im Ganzen 50 C.-Ctm. der Lösung A injieirt. Diese Lösung vor der Injection auf ihre Wirksamkeit auf "Salzplasma" gepruft, erwies sich als sehr fermentarm, obgleich sie ebenso zubereitet war, wie die zu den bereits angeführten Versuchen benutzten; sie wirkte namentlich etwa 20 mal langsamer auf das "Salzplasma" als die letzteren. Die Erklärung hierfür liegt im ursprünglich geringen Fermentgehalte des zur Darstellung dieser Lösung benutzten Blutserums, der überhaupt in weiten Grenzen schwankt. Entsprechend dem geringen Fermentgehalte der Lösung wurde auch die Injection sehr gut vertragen, abgesehen von etwas beschleunigter und erschwerter Respiration. Das Thier wurde durch einen Irrthum des Dieners in meiner Abwesenheit getödtet, wovon ich indess so spät Kunde erhielt, dass ich von einer Section absehen musste.

Versuch 10. Einem Kaninchen von $1320 \mathrm{Grm}$. wurden am 2/IX. 79. 20 C.-Ctm. der Lösung A in die Vena jugul. dextr. extern. injicirt. Während der sehr langsamen Injection tritt Defäcation ein, das Thier bekommt eine sehr heftige Dyspnoe, welche von heftigen asphyktischen Anfällen begleitet ist, es tritt aber weder während der Injection, noch auch unmittelbar nach derselben der Tod ein, sondern erst nach etwa 10 Minuten und zwar erfolgt er auch hier, wie in allen iubrigen Fällen, durch Asphyxie. Die Section ergab zwar im Herzen keine Gerinnsel, wohl aber war die Arteria pulmonalis bis in ihre feinsten Verzweigungen hinein mit Gerinnseln verstopft.

Wir haben jetzt also gesehen, dass man durch Injection von reinen Fermentlösungen im Stande ist das circulirende Blut in den lebenden Gefässen momentan zur Gerinnung zu bringen und dadurch den Tod herbeizuführen. Sehen wir jetzt zu, wie sich die durch Hämatin gefärbten Lösungen verhalten.

Versuch 11. Einem Kater von $2100 \mathrm{Grm}$. werden sehr langsam 20 C.-Ctm. der Lösung B in die Vena jugul. sin. ext. injicirt. Während der Injection wird das Thier asphyktisch und stirbt, ehe die Injection zu Ende 
gebracht ist; die sofort angestellte Section ergibt dieselben Befunde wie die der Versuche 1 und 2.

Versuch 12. Einem Kaninchen von 1100 Grm. werden sehr langsam und vorsichtig in die Vena jugul. sin. ext. 20 C.-Ctm. der Lösung B injicirt. Während der Injection bekommt das Thier asphyktische Krämpfe und stirbt. Der Sectionsbefund ergibt anch hier das rechte Herz vollgestopft von Gerinnseln, ansserdem lassen sich aus der Vena cava ascend. sehr feste, zusammenhängende, lange Gerinnsel herausziehen.

Versuch 13. Derselbe wurde angestellt, weil im vorigen Versuche ein Theil der zu injicirenden Flüssigkeit verloren gegangen war und somit nicht einmal annähernd ein Maassstab für die zur tödtlichen Wirkung nöthige Quantität der Fermentlösung erhalten wurde. Es wurden also einem Kaninchen von $1000 \mathrm{Grm}$. langsam in die Vena jugul. sin. ext. 10 C.-Ctm. der Lösung B injicirt; es sind kaum ein paar Cnbikcentimeter übergeflossen, als auch das Thier schon Krämpfe bekommt und mit dem Ende der Injection ist es todt. Der Sectionsbefund ist hier genau derselbe wie im vorigen Versuche.

Ich habe ferner zwölf Fröschen nacheinander 1-2 C.-Ctm. der Lösung A sowohl als B in die Vena cava ascendens oder in die Vena abdominalis injicirt; die Thiere blieben leben und lebten noch sehr lange, jedesmal aber fand ich unmittelbar nach der Injection alle grösseren Gefässe mit Fibringerinnseln, die sich in langen Fäden herausziehen liessen, vollgestopft.

Zum Schlusse dieser Versuchsreihe bemerke ich, dass ich mir die zu injicirenden Fermentlösungen stets unmittelbar vor Anstellung des Versuches herstellte. Ich fand nämlich, dass eine Fermentlösung, welche unmittelbar nach der Herstellung tödtlich wirkte, nachdem sie den Nachmittag und die Nacht über im Keller gestanden, doch schon so viel von ihrer Wirksamkeit eingebüsst hatte, dass sie nicht sogleich, sondern erst nach mehreren Stunden tödtlich wirkte, während eine aus demselben Material dargestellte frische Fermentlösang wiederum momentan tödtete. Auch durch die Reactionsfliussigkeit liess sich der Unterschied in der Wirksamkeit der gestandenen und der frisch bereiteten Fermentlösungen, die natürlich unter übrigens ganz gleichen Bedingungen hergestellt wurden, nachweisen.

\section{Reihe II.}

Wenden wir uns jetzt den Fällen zu, in welchen zwar nicht der Tod die unmittelbare Folge der Fermentinjection war, wohl aber, wie mir scheint, ein sehr charakteristischer mit Temperatursteigerungen verkniupfter Symptomencomplex. Die Resultate dieser Versuche ergeben sich unmittelbar aus den beifolgenden Tabellen. 
Versuch 1.

\begin{tabular}{|c|c|c|c|c|}
\hline $\begin{array}{l}\mathbb{E} \\
\stackrel{\Xi}{\Xi} \\
\stackrel{\Xi}{*} \\
\end{array}$ & 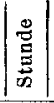 & 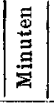 & 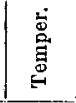 & Bemerkungen \\
\hline $\begin{array}{l}11 / \mathrm{VI} . \\
1879 .\end{array}$ & \begin{tabular}{|r|}
5 \\
5 \\
6 \\
6 \\
7 \\
7 \\
8 \\
9 \\
9 \\
10
\end{tabular} & $\left|\begin{array}{r}20 \\
45 \\
45 \\
20 \\
35 \\
5 \\
20 \\
45 \\
50\end{array}\right|$ & \begin{tabular}{|l}
37,6 \\
38,9 \\
39,3 \\
\\
39,7 \\
39,9 \\
40,1 \\
40,3 \\
40 \\
39,5 \\
39,2 \\
\\
39,2 \\
39,1 \\
39 \\
39,3 \\
39,4 \\
39,1 \\
39,3 \\
39,2
\end{tabular} & $\begin{array}{l}\text { Injection von } 30 \text { C.-Ctm. der Lösung A, die Injection wird } \\
\text { gut vertragen, es sinkt aber während derselben die Tem- } \\
\text { peratur, sie beträgt } \\
\text { Das Thier wird losgebunden und befindet sich scheinbar } \\
\text { ganz wohl, es läuft umher und ist munter.' } \\
\text { Das Thier zittert recht heftig, ist aber sonst munter, es } \\
\text { entleert festen Koth und Harn. } \\
\text { Sehr heftiges Zittern, schüttelfrostähnlich, heftiges Kollern } \\
\text { im Leibe, sonst nichts Abnormes. } \\
\text { Status idem. } \\
\text { Status idem. } \\
\text { Status idem, nur ist das Zittern äusserst heftig. } \\
\text { Das Thier beginnt sich zu erholen, das Zittern lässt all- } \\
\text { mählich nach. } \\
\text { Das Zittern hat aufgehört, das Thier ist munter und frisst } \\
\text { mit grossem Appetit. } \\
\text { Status idem. } \\
\text { Das Thier ist vollständig munter und hat guten Appetit. } \\
\text { Von Seiten der Wunde sind keinerlei Complicationen auf- } \\
\text { getreten, die Ränder sind primär verklebt, in der Umge- } \\
\text { bung keine Spur einer entzündlichen Reaction. }\end{array}$ \\
\hline
\end{tabular}

Die weitere genaue Beobachtung wird aufgegeben, am 18/VI. 79. wird der Verband entfernt, es ist eine schöne, leichte Narbe vorhanden und am 26/VI. 79. dient das Thier zu einem Versuche in der Reihe IIIA (Versuch 1).

Ich habe nur in diesem Versuche und in dem ersten Versuche der Reihe IIIA die Thiere vor der Injection längere Zeit aufgebunden gehalten; in den übrigen Versuchen habe ich dieselben nur kurz vor der Injection aufgebunden, sie durch Einhüllen in Watte möglichst vor Abkühlung geschuttt und dann gleich nach der Injection wieder losgebunden, denn da ich die Thiere immer nur im freien Zustande beobachtete, hielt ich es nicht für nothwendig, sie längere Zeit in gezwungener Lage zu erhalten. 
Versuch 2.

\begin{tabular}{|c|c|c|c|c|}
\hline 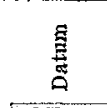 & 焉 & 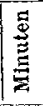 & 悹 & Bemerkungen \\
\hline \multirow{6}{*}{ 9/VIII. } & & & & $\begin{array}{l}\text { Versuchsthier: } \mathrm{Zu} \text { diesem Versuche diente dasselbe Thier, } \\
\text { welches in der Reihe III A zum Versuch } 2 \text { gebraucht } \\
\text { worden war. Fs wog jetzt } 5150 \text { Grm. Von Seiten der } \\
\text { damaligen Wunde war durchaus keine Contraindication } \\
\text { zu diesem Versuche geboten. }\end{array}$ \\
\hline & 10 & 15 & $38, \pi$ & \multirow{8}{*}{ Temperaturen vor dem Versuche. } \\
\hline & $\begin{array}{l}3 \\
8\end{array}$ & - & $\begin{array}{l}38,5 \\
38,8\end{array}$ & \\
\hline & 10 & - & 38,7 & \\
\hline & 3 & 5 & 38,9 & \\
\hline & & 30 & 38,8 & \\
\hline 12/VIII. & $\begin{array}{r}10 \\
3\end{array}$ & $\begin{array}{l}30 \\
45\end{array}$ & $\begin{array}{l}38,7 \\
39\end{array}$ & \\
\hline \multirow{19}{*}{ 13/VIII. } & 8 & 30 & 38,8 & \\
\hline & 9 & 45 & 38,7 & \\
\hline & $\begin{array}{l}2 \\
3\end{array}$ & $\begin{array}{l}50 \\
35\end{array}$ & $\underline{38,9}$ & Das Thier wird aufgebunden. \\
\hline & 3 & 50 & 38,4 & $\begin{array}{l}\text { Die Jugularis dextr. extern. ist freigelegt und die Canüle } \\
\text { eingebunden. }\end{array}$ \\
\hline & 4 & 一 & 38 & $\begin{array}{l}\text { Injection von } 58 \mathrm{C} \text {.-Ctm. der Lösung } \mathrm{A} \text { beendet. Die In- } \\
\text { jection wurde gut vertragen. }\end{array}$ \\
\hline & 4 & 15 & 38 & $\begin{array}{l}\text { Das Thier wird losgebunden, es entleert noch auf dem } \\
\text { Brette einen breiigen Stuhl und beginnt gleich nach dem } \\
\text { Losbinden heftig zu zittern, geht aber sonst munter umher. }\end{array}$ \\
\hline & 4 & 40 & 39,4 & $\begin{array}{l}\text { Das Thier zittert am ganzen Leibe sehr heftig, liegt be- } \\
\text { ständig und scheint sehr krank zu sein, es entleert unter } \\
\text { heftigen Tenesmen einen dünnen Stuhl. }\end{array}$ \\
\hline & 5 & -- & 39,6 & Der Zustand des Thieres wird offenbar immer schlimmer \\
\hline & 5 & 25 & 40 & und schlimmer. \\
\hline & 5 & 45 & - & Das Thier erbricht. \\
\hline & 6 & - & 41,5 & $\begin{array}{l}\text { Das Thier ist aufs äusserste ermattet, richtet man es auf, } \\
\text { so fällt es kraftlos wieder zusammen; es ist apathisch, } \\
\text { fast somnolent. }\end{array}$ \\
\hline & 6 & 30 & 40,9 & $\begin{array}{l}\text { Unter sehr heftigen Tenesmen wird ein flüssiger schleimiger } \\
\text { Stuhl entleert, welcher zuletzt nur aus Schleimmassen } \\
\text { ohne jegliche fäculente Beimischung besteht. }\end{array}$ \\
\hline & 7 & - & 40,7 & \multirow{5}{*}{$\begin{array}{l}\text { Der Zustand des Thieres bessert sich allmählich; die Te- } \\
\text { nesmen lassen nach, das Thier wird immer munterer und } \\
\text { munterer, das Zittern hört auf; das Thier erhebt sich, } \\
\text { beginnt umberzugehen. }\end{array}$} \\
\hline & 7 & 30 & 40,7 & \\
\hline & & $\overline{20}$ & 40,5 & \\
\hline & $\begin{array}{l}0 \\
9\end{array}$ & - & 30 & \\
\hline & 9 & 30 & 39,5 & \\
\hline & 10 & - & 39,3 & $\begin{array}{l}\text { Das Thier ist munter, hat offenbar vollständig sich erholt } \\
\text { und frisst mit grossem Appetit. }\end{array}$ \\
\hline & $\begin{array}{l}11 \\
12\end{array}$ & $\overline{30}$ & $\begin{array}{l}39 \\
38,8\end{array}$ & Status idem. \\
\hline \multirow[t]{3}{*}{14 NIII. } & 8 & 45 & 38,9 & \multirow{3}{*}{$\begin{array}{l}\text { Das Thier ist vollständig gesund, frisst mit grossem Ap- } \\
\text { petit und entleert einen festen Stuhl. Die Wunde ist } \\
\text { vollkommen reactionslos und primär verklebt. }\end{array}$} \\
\hline & $\begin{array}{r}12 \\
4\end{array} \mid$ & 45 & $\begin{array}{l}39,2 \\
39,4\end{array}$ & \\
\hline & 7 & 45 & 39,3 & \\
\hline \multirow{2}{*}{ 15/VIII. } & 9 & 20 & $\begin{array}{r}39,6 \\
39\end{array}$ & \multirow{2}{*}{ Status idem. Die weitere Beobachtung wird aufgegeben. } \\
\hline & 6 & 45 & $\begin{array}{l}39,5 \\
39,2\end{array}$ & \\
\hline
\end{tabular}


Versuch 3.

\begin{tabular}{|c|c|c|c|c|}
\hline 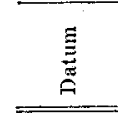 & 总 & 总 & 离 & Bemerkungen \\
\hline \multirow{6}{*}{$\begin{array}{l}16 / \text { VIII. } \\
1879 . \\
17 / \text { VIII. }\end{array}$} & & & & Versuchsthier: Junger Hund, 6650 Grm. schwer. \\
\hline & 9 & 30 & 38,9 & \\
\hline & 2 & - & 39,2 & \multirow{8}{*}{ Temperaturen vor dem Versuche. } \\
\hline & & 30 & 39,2 & \\
\hline & 10 & 30 & 39,1 & \\
\hline & 2 & $\begin{array}{l}30 \\
15\end{array}$ & 39,3 & \\
\hline \multirow[t]{20}{*}{ 18/VIII. } & 9 & 15 & 38,7 & \\
\hline & 10 & 55 & 38,4 & \\
\hline & 12 & 40 & 38,7 & \\
\hline & $\begin{array}{l}3 \\
3\end{array}$ & $\overline{10}$ & 38,9 & \\
\hline & 3 & 25 & 38,5 & $\begin{array}{l}\text { Die Jugularis dextr. extern. ist freigelegt und die Canüle } \\
\text { eingebunden. }\end{array}$ \\
\hline & 3 & 35 & 38,2 & Injection von 77 C.-C'tm. der Lösung A beendet. \\
\hline & 3 & 45 & - & Das Thier wird losgebunden. \\
\hline & 4 & 5 & 39 & $\begin{array}{l}\text { Das Thier ist bereits sichtbar krank, es beginnt sehr heftig } \\
\text { zu zittern, hat starke Tenesmen und ist sehr traurig und } \\
\text { verstimmt, es scheint an Uebelkeiten zu leiden. }\end{array}$ \\
\hline & 4 & 20 & 39,2 & $\begin{array}{l}\text { Das Thier erbricht zweimal hintereinander, sein Zustand } \\
\text { hat sich bedeutend verschlimmert. }\end{array}$ \\
\hline & 4 & 50 & 39,4 & $\begin{array}{l}\text { Während der Temperaturmessung drängt das Thier sehr } \\
\text { heftig und entleert gleich nach derselben einen flüssigen } \\
\text { Stuhl. }\end{array}$ \\
\hline & 5 & 20 & 39,6 & $\begin{array}{l}\text { Das Thier beleckt sich beständig das Maul und macht hef- } \\
\text { tige Brechbewegungen. }\end{array}$ \\
\hline & 5 & 45 & 39,9 & $\begin{array}{l}\text { Das Thier scheint sehr stark zu leiden, es liegt beständig, } \\
\text { zittert äusserst heftig, athmet sehr frequent und erschwert } \\
\text { und macht beständig Brechbewegungen. }\end{array}$ \\
\hline & 6 & 10 & 40,9 & $\begin{array}{l}\text { Vor der Temperaturmessung entleert das Thier unter äus- } \\
\text { serst heftigen Tenesmen zwei dünnflüssige mit Blut und } \\
\text { Schleim untermischte Stühle, gleich nach derselben er- } \\
\text { folgt wieder ein gleicher Stuhl unter denselben Bedin- } \\
\text { gungen. }\end{array}$ \\
\hline & 6 & 45 & 40,5 & $\begin{array}{l}\text { Es ertolgt wieder ein diarrhoischer Stuhl, welcher ohne } \\
\text { jegliche fäculente Beimischung nur aus Blut und Schleim } \\
\text { besteht, die Uebelkeiten halten an. }\end{array}$ \\
\hline & 7 & 15 & 40,3 & $\begin{array}{l}\text { Es erfolgen noch immer blutjge Stüble, aber der Zustand } \\
\text { des Thieres scheint sich sonst etwas gebessert zu haben, } \\
\text { die Uebelkeiten und das Zittern haben etwas nachge- } \\
\text { lassen, ebenso erfolgen die Stühle seltener. }\end{array}$ \\
\hline & 8 & 15 & 39,9 & $\begin{array}{l}\text { Das Thier hat sich etwas erholt, es bewegt sich jetzt } \\
\text { etwas mehr und frisst etwas Fleisch. }\end{array}$ \\
\hline & 8 & 45 & 39,5 & Der Zustand bessert sich sichtlich. \\
\hline & & 30 & 39,3 & Status idem. \\
\hline & 10 & 15 & 38,8 & $\begin{array}{l}\text { Das Thier ist vollständig erholt und munter, es frisst mit } \\
\text { Appetit. }\end{array}$ \\
\hline & 12 & 30 & 38,5 & Status idem. \\
\hline \multirow{4}{*}{$19 /$ VIII. } & 9 & 30 & 39,2 & \\
\hline & 1 & 50 & 38,9 & lier ist vollstăndig munter und erholt, es frisst mit \\
\hline & 5 & 15 & 38,9 & Appetit und entleert festen Koth. \\
\hline & 8 & 45 & 38,6 & \\
\hline \multirow[t]{2}{*}{ 20/VIII. } & 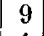 & 45 & 39,1 & Status idem. Die W \\
\hline & $\begin{array}{l}1 \\
4 \\
8\end{array}$ & $\left|\begin{array}{l}30 \\
15 \\
10\end{array}\right|$ & $\begin{array}{l}38,7 \\
39 \\
38,5\end{array}$ & $\begin{array}{l}\text { einen Tropfen Secret verheilt. Die weitere Beobachtung } \\
\text { wird aufgegeben. }\end{array}$ \\
\hline
\end{tabular}


Fersuch 4.

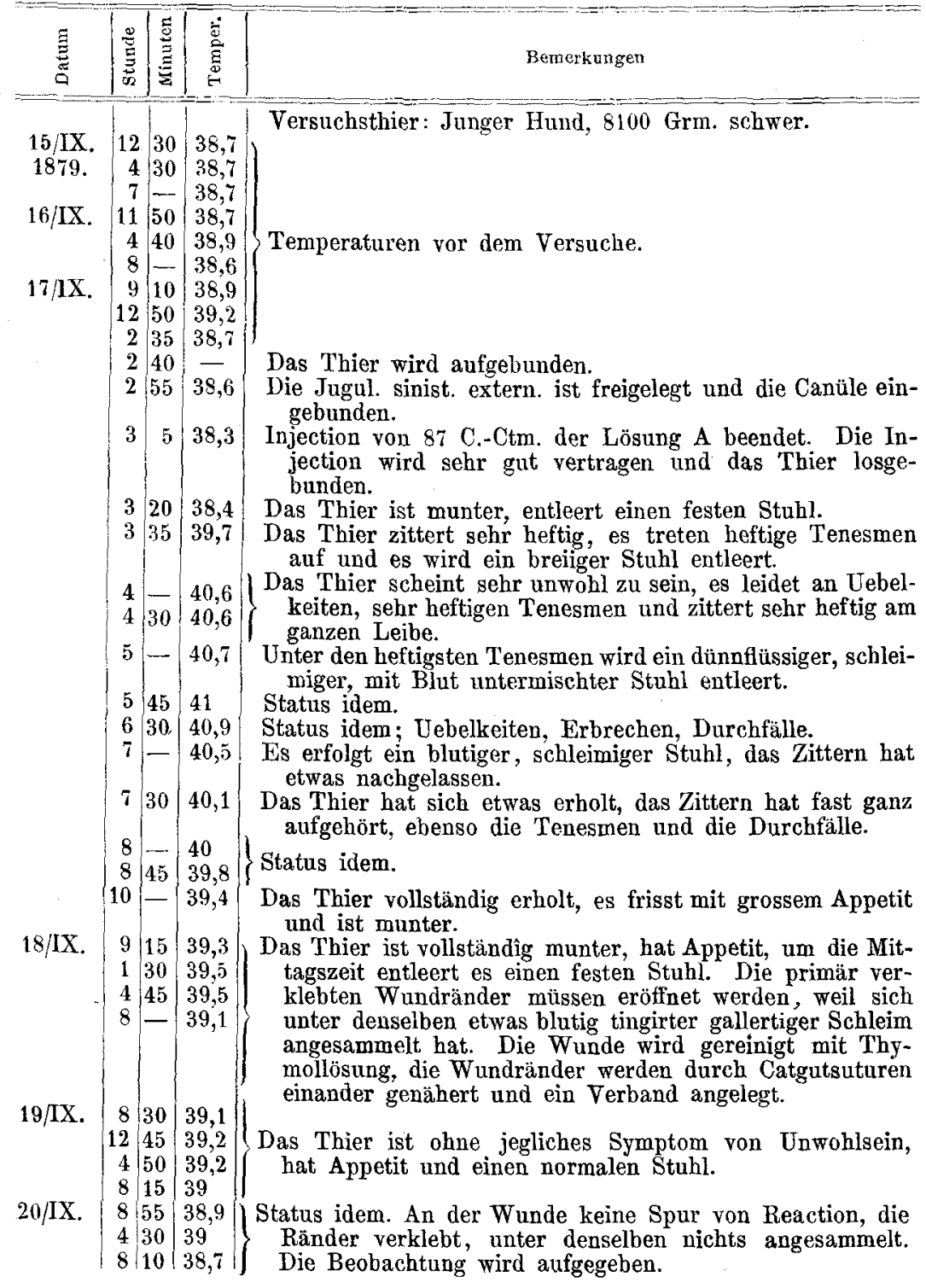

Versuch 5 .

\begin{tabular}{l|l|l|l|l|l} 
15/IX. & 9 & 30 & 39,1 & Versuchsthier: Junge Hündin, 6000 Grm. schwer. \\
1879. & 4 & - & 39,3 \\
& 7 & 30 & 39
\end{tabular} \mid $\begin{aligned} & \text { Temperaturen vor dem Versuche. } \\
& \end{aligned}$ 


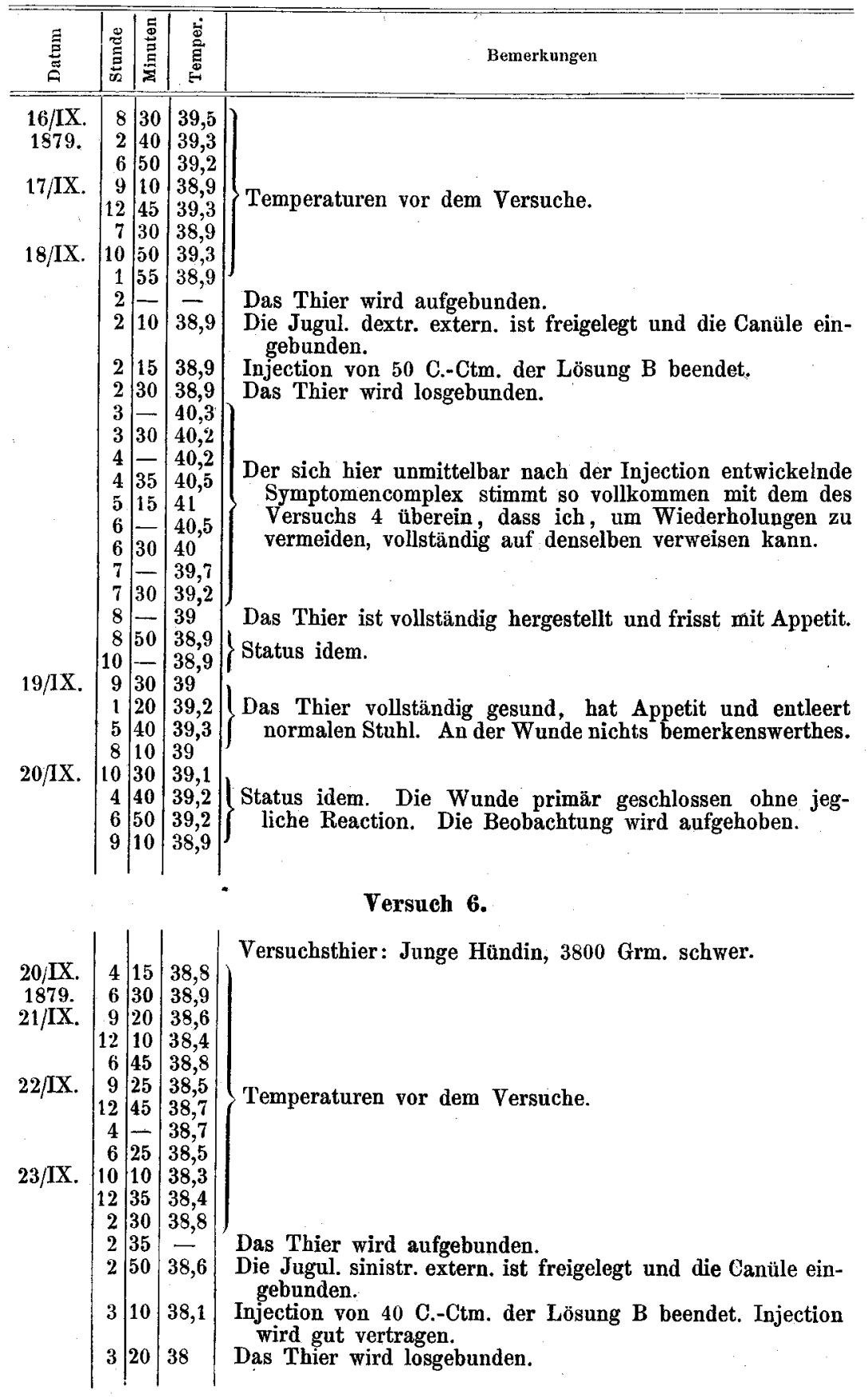


Ein Beitrag zur Lehre von der Thrombosis und vom Fieber.

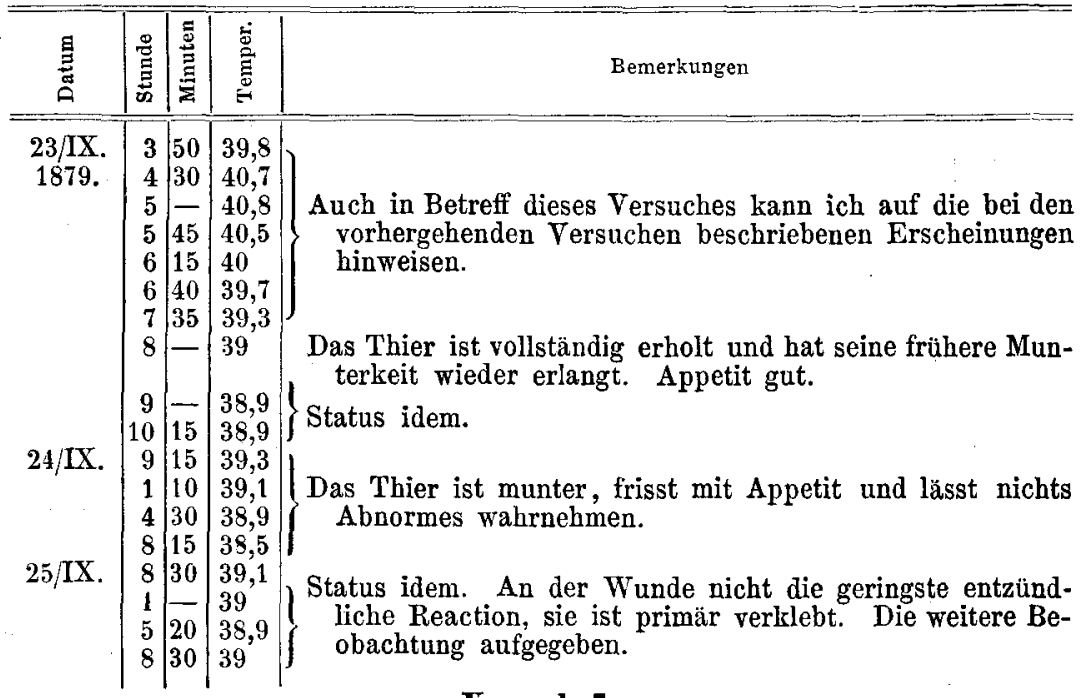

\section{Versuch 7.}

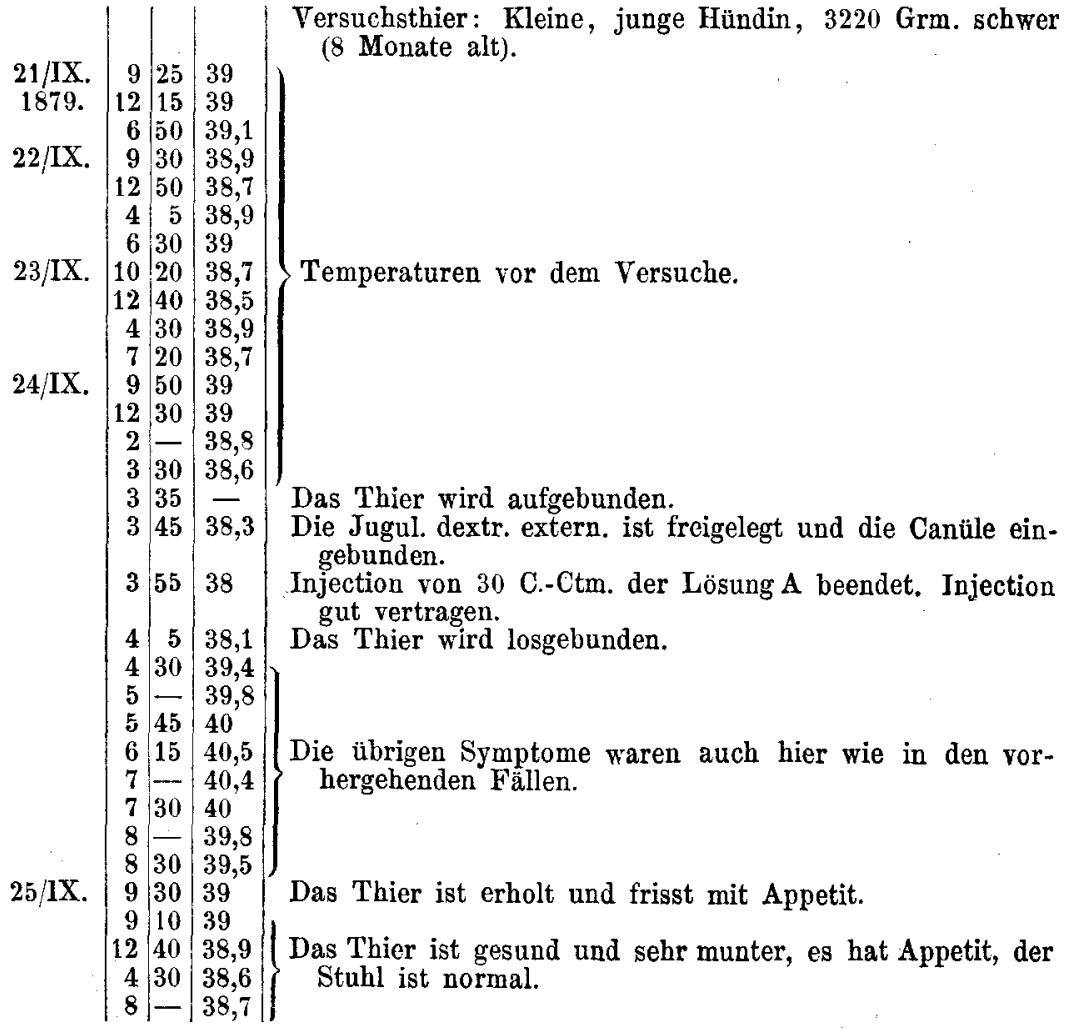




\begin{tabular}{|c|c|c|c|c|}
\hline$\stackrel{g}{g}$ & 总 & 递 & 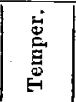 & Bemerkungen \\
\hline $\begin{array}{c}26 / L X . \\
1879 .\end{array}$ & $\begin{array}{r}10 \\
1 \\
4 \\
7\end{array}$ & $\begin{array}{l}15 \\
30 \\
25 \\
30\end{array}$ & $\begin{array}{l}39,1 \\
38,9 \\
39 \\
38,9\end{array}$ & $\begin{array}{l}\text { Status idem. Von Seiten der Wunde keine Complication. } \\
\text { Die weitere Beobachtung wird aufgegeben. }\end{array}$ \\
\hline
\end{tabular}

Versuch 8.

8/VIII. 9 \begin{tabular}{l|l|l|}
9 & 15 & 38,7
\end{tabular} $1879 . \quad 1230 \quad 38,5$

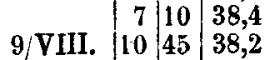

$3-38,3$

\begin{tabular}{l|l|l|l}
7 & 15 & 38,6
\end{tabular}

8 30 37,9

10/VIII. 10 15 37,7

12 15 37,8

\begin{tabular}{r|r|r|r}
3 & 5 & 37,7 \\
3 & & 37,4 \\
\hline
\end{tabular}

3 15 37,4

33037 Injection von 45 C.-Ctm. der Lösung A beendet, das Thier ist sehr unruhig, verträgt aber sonst die Injection ohne besonderes Symptom.

34536 Das Thier wird losgebunden.

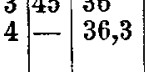

\begin{tabular}{l|l|l|l|l} 
& 35 & 37,8 \\
\end{tabular}

$\int^{3}$

$5-39$

$\begin{array}{llll}5 & 30 & 39,5\end{array}$

$\mathrm{C}_{6}$

$630 \quad 39,9$

$7-39,7$

$\begin{array}{llll}7 & 30 & 39,6\end{array}$

$8-39,3$

$\begin{array}{llll}8 & 30 & 39\end{array}$

9 - 39

$930 \quad 38,9$

$10-38,9$

$10 \quad 30 \quad 39,1$

11/VIII. \begin{tabular}{r|r|r|r}
9 & 50 & 39,4 \\
12 & - & 39,2
\end{tabular} Das Thier ist gesund. An der Wunde keine Spur von

$\left.\begin{array}{rrr}12 & -39,2 \\ 40 & 39,1\end{array}\right\}$ Reaction, dieselbe war wegen ihrer Tiefe drainirt worden,

\begin{tabular}{l|l|l|}
8 & 15 & 39 \\
\hline
\end{tabular}

\begin{tabular}{l|l|l|l|}
$12 /$ VIII. & 8 & 30 & 38,6
\end{tabular}

$\begin{array}{llll}2 & 15 & 38,8 \\ & 6 & \end{array}$

\begin{tabular}{l|l|l|}
6 & 45 & 38,9 \\
\hline
\end{tabular}

\begin{tabular}{l|l|l|}
9 & 10 & 38,5
\end{tabular}
An dem Thiere nichts Abnormes wahrnehmbar, es entleert einen festen Stuhl.

Status idem. Während der Temperaturmessung quillt aus dem After eine grosse Menge blutigen Schleims, unmittelbar nach derselben wird ein etwas weniger fester Stuhl mit Blut untermischt entleert.

Status idem.

Das Thier ist offenbar sehr krank; es entleert mehrere mit Schleim und Blut untermischte Stühle von mehr breiiger Consistenz, es athmet sehr frequent und sichtlich erschwert, es sitzt traurig und zusammengekauert in einer Ecke des Käfigs und miaut kläglich.

Status idem. Das Thier hat sehr durch Tenesmen zu leiden, es ist sehr matt und angegriffen.

Status idem.

Der Zustand scheint sich etwas gebessert zu haben, die Athmung ist etwas freier geworden, die Tenesmen haben nachgelassen, es ist kein Stuhl weiter erfolgt, das Thier ist aber immer noch sehr matt und angegriffen.

Status idem.

Das Thier hat sich fast vollkommen erholt und ist bedeutend munterer geworden.

Das Thier frisst mit grossem Appetit.

Das Thier ist vollständig erholt. die Wundränder um das Drainrohr verklebt.

Status idem. Das Drainrohr wird entfernt, die Wunde vorzüglich geschlossen. Die weitere Beobachtung wird aufgegeben. 
Versuch 9.

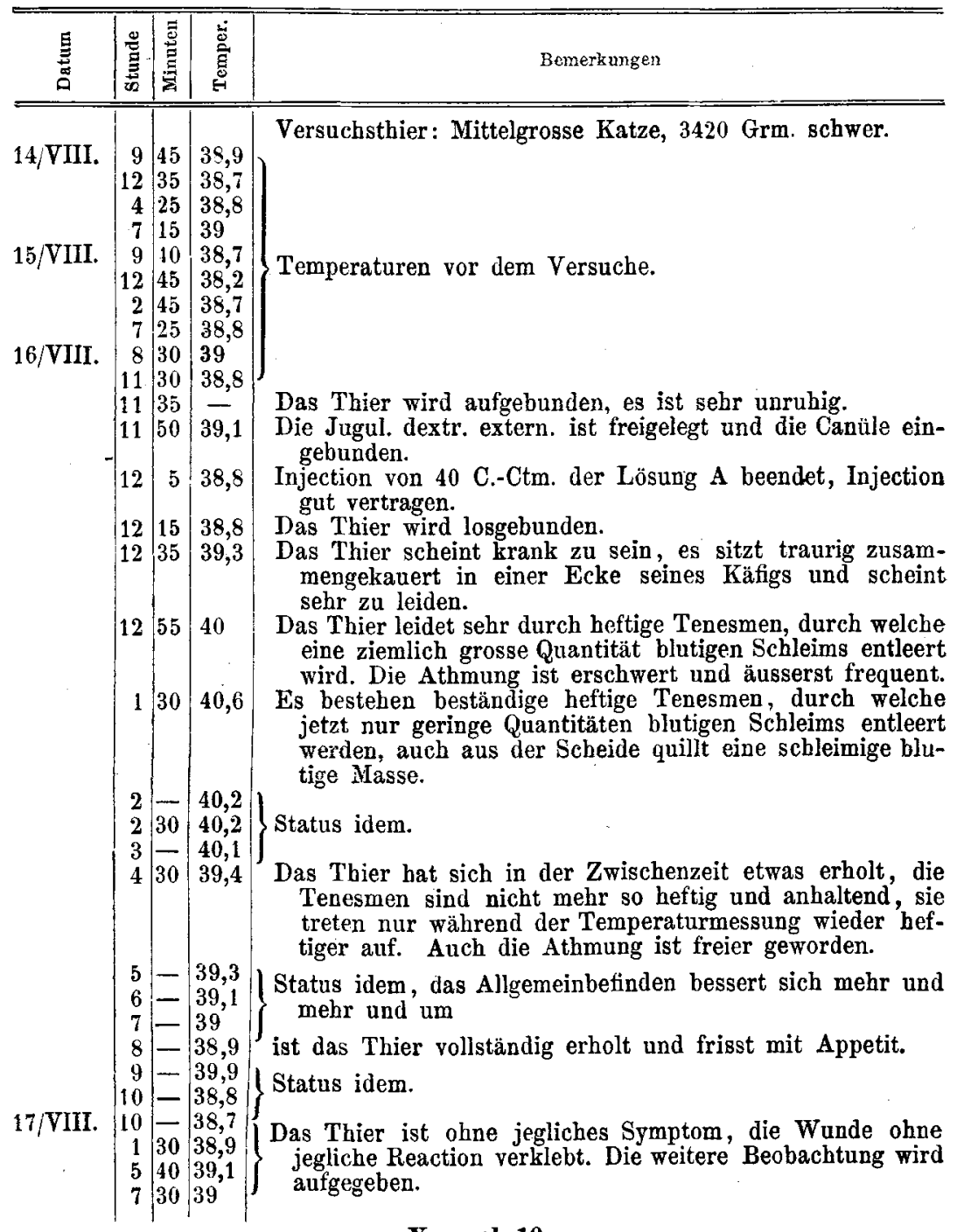

Versuch 10.

$\left.\begin{array}{c|r|r|r|l}22 / \text { VIII. } & 9 & 30 & 38,5 \\ 1879 . & 12 & 20 & 38,7 \\ 23 / \text { VIII. } & 4 & 10 & 38,4 \\ 7 & 30 & 38,9 \\ 10 & 15 & 38,7 \\ 2 & 10 & 39 \\ & 6 & 40 & 38,8 \\ 9 & - & 39\end{array}\right\}$ Tersuchsthier : Kater, 2950 Grm. schwer. 


\begin{tabular}{|c|c|c|c|c|}
\hline $\begin{array}{l}\text { 吾 } \\
\text { 吕 }\end{array}$ & 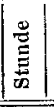 & 离 & & Bemerkungen \\
\hline 26/VIII. & $\begin{array}{r}11 \\
12 \\
12 \\
1 \\
1 \\
2 \\
2 \\
3 \\
4 \\
5 \\
6 \\
7 \\
8 \\
9 \\
10 \\
3 \\
5 \\
8 \\
9 \\
1 \\
4 \\
7\end{array}$ & \begin{tabular}{|c|}
35 \\
10 \\
30 \\
30 \\
5 \\
45 \\
20 \\
15 \\
- \\
- \\
- \\
30 \\
50 \\
15 \\
30 \\
30 \\
50 \\
15
\end{tabular} & \begin{tabular}{|l}
37,6 \\
38,4 \\
38,7 \\
39,1 \\
39,4 \\
39,9 \\
40,4 \\
40,3 \\
40 \\
39,6 \\
39,2 \\
39 \\
38,9 \\
38,8 \\
38,5 \\
38,7 \\
38,9 \\
39,2 \\
38,7 \\
39,1 \\
39 \\
38,8
\end{tabular} & $\begin{array}{l}\text { Temperaturen vor dem Versuche. } \\
\text { Das Thier wird aufgebunden. } \\
\text { Die Jugul. sinist. extern. ist freigelegt und die Ca nüle ein- } \\
\text { gebunden. } \\
\text { Injection von } 40 \text { C.-Ctm. der Lösung beendet, die Injection } \\
\text { wird gut vertragen. } \\
\text { Das Thier wird losgebunden und ist munter. } \\
\text { Tenesmen beginnen. } \\
\text { Es entwickelt sich der vollständige im vorigen Falle aus- } \\
\text { führlich geschilderte Symptomencomplex; ich verweise } \\
\text { daher auf denselben. } \\
\text { Das Thier hat sich etwas erholt, ist aber noch immer sehr } \\
\text { matt und angegriffen. } \\
\text { Das Thier ist bedeutend munterer, hat sich vollständig } \\
\text { erholt und frisst mit Appetit. } \\
\text { Status idem. } \\
\text { Das Thier ist vollständig gesund, frisst mit Appetit, der } \\
\text { Stuhl ist normal. } \\
\text { Status idem. Von Seiten der Wunde keine Complication, } \\
\text { sie ist schön primär verklebt. Die weitere Beobachtung } \\
\text { wird aufgegeben. }\end{array}$ \\
\hline
\end{tabular}

\section{Versuch 11.}

\begin{tabular}{|c|c|c|c|}
\hline \multirow{4}{*}{$\begin{array}{c}22 / \text { VIII. } \\
1879 .\end{array}$} & 8 & 30 & 38,5 \\
\hline & 12 & 50 & 38,8 \\
\hline & 4 & 40 & 38,4 \\
\hline & 7 & 15 & 37,9 \\
\hline \multirow[t]{4}{*}{ 23/VIII. } & 9 & 10 & 37,9 \\
\hline & 12 & 15 & 38,1 \\
\hline & 3 & 45 & 38,5 \\
\hline & 6 & 50 & 38,4 \\
\hline \multirow{12}{*}{ 24/VIII. } & o & 100 & $\begin{array}{l}31,9 \\
38,\end{array}$ \\
\hline & 11 & 50 & 39 \\
\hline & 11 & 55 & - \\
\hline & 12 & 5 & 38,5 \\
\hline & 12 & 15 & 38 \\
\hline & 12 & 25 & 37,9 \\
\hline & 12 & $50 \mid$ & 39,3 \\
\hline & 1 & 15 & 39,8 \\
\hline & 2 & -1 & $40^{\circ}$ \\
\hline & 2 & 30 & 40,5 \\
\hline & & -1 & 40 \\
\hline & & & \\
\hline
\end{tabular}

Versuchsthier: Katze, 2580 Grm. schwer.

Temperaturen vor dem Versuche.

Das Thier wird aufgebunden.

Die Jugul. sinist. extern. ist freigelegt und die Canüle eingebunden.

Injection von $30 \mathrm{C}$.-Ctm. der Lösung $\mathrm{B}$ beendet. Injection gut vertragen.

Das Thier wird losgebunden.

Das Thier zittert sehr heftig und es entwickelt sich das oft geschilderte Bild, nur ist in diesem Falle sehr häufiges Erbrechen vorhanden. In der Zeit von $1 \mathrm{~h} .5 \mathrm{~m}$. bis $1 \mathrm{~h} .40 \mathrm{~m}$. erbricht das Thier siebenmal. 


\begin{tabular}{|c|c|c|c|c|}
\hline 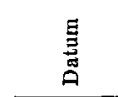 & 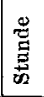 & 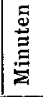 & 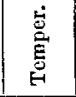 & Bemerkungen \\
\hline $\begin{array}{c}24 / \text { VIII. } \\
1879 .\end{array}$ & $\begin{array}{l}5 \\
5 \\
6 \\
7 \\
8\end{array}$ & $\frac{-3}{30}$ & $\begin{array}{l}39,7 \\
39,7 \\
39,7 \\
39,5 \\
39 \\
38,7 \\
38,5\end{array}$ & $\begin{array}{l}\text { Der Zustand des Thieres bessert sich allmählich, das Er- } \\
\text { brechen hört auf, die Tenesmen lassen nach, ebenso das } \\
\text { Zittern. } \\
\text { Status idem. } \\
\text { Das Thier hat sich fast vollständig erholt, es ist nur noch } \\
\text { matt und angegriffen. } \\
\text { Das Thier ist vollkommen erholt und frisst mit grossem } \\
\text { Appetit. }\end{array}$ \\
\hline 25/VIII. & $\begin{array}{r}8 \\
11 \\
3 \\
6 \\
9\end{array}$ & $\begin{array}{l}15 \\
15 \\
30 \\
15\end{array}$ & $\begin{array}{l}37,5 \\
37,8 \\
38 \\
38,1 \\
37,9\end{array}$ & $\begin{array}{l}\text { Das Thier ist vollständig wohl, hat guten Appetit, an der } \\
\text { Wunde ist nichts Abnormes zu constatiren, die Ränder } \\
\text { sind primär verklebt, nur eine ganz kleine Stelle ist offen } \\
\text { und durch diese lässt sich etwas seröse gallertige Flüs- } \\
\text { sigkeit entleeren. }\end{array}$ \\
\hline 26/VIII. & 9 & $\begin{array}{l}15 \\
30 \\
10 \\
15\end{array}$ & $\begin{array}{l}37,8 \\
38,1 \\
37,9 \\
37,6\end{array} \mid$ & $\begin{array}{l}\text { Status idem. An der Wunde nichts von einer entzünd- } \\
\text { lichen Reaction wahrzunehmen. Die weitere Beobacht- } \\
\text { ung wird aufgegeben. }\end{array}$ \\
\hline
\end{tabular}

\section{Versuch 12.}

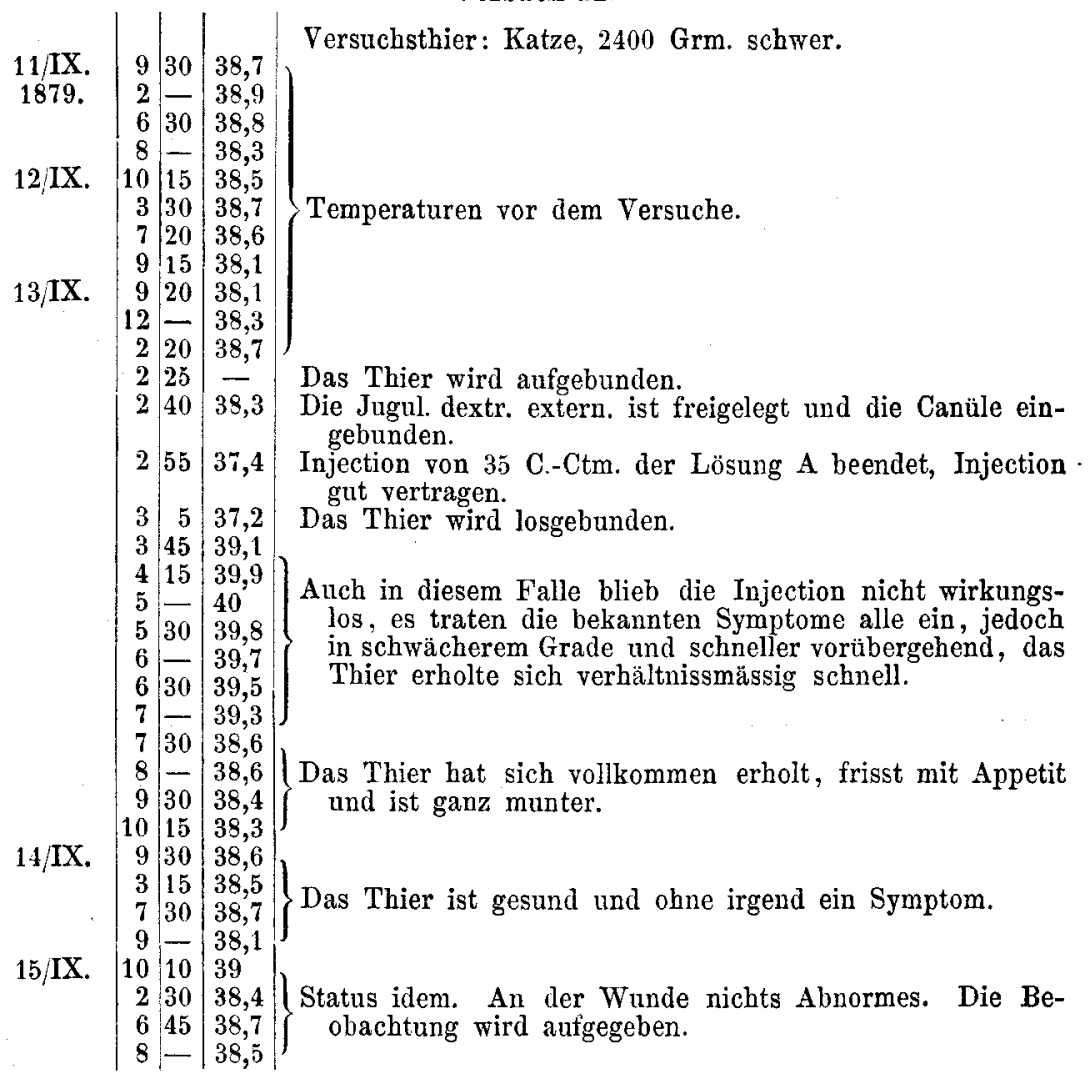


Aus den vorstehenden Versuchen geht nun klar hervor, dass die Injecton von Fermentlösungen, sei es rothen, sei es farblosen, ins Blut im Stande ist, ein Symptomenbild hervorzurufen, welches sehr auffallende Aehnlichkeit mit der sogenannten putriden Intoxication hat; đe hohen Temperaturen, die bedeutende Störung des Allgemeinbefindens, das Erbrechen, die Tenesmen, die blutigen Durchfälle, Alles das stimmt so auffallend mit den die putride Intoxication begleitenden Erscheinungen überein, dass es sehr verlockend erscheint, an eine Identität beider Symptomencomplexe als auf gemeinsamer Basis beruhend zu denken. Hierbei steht mir noch folgende Erfahrung zur Seite. Ich mischte ein ziemlich frisches (etwa 8 Tage altes) Macerationswasser mit "Salzplasma" und nach verhäItnissmässig kurzer Zeit war vollständige Gerinnung eingetreten. Freilich gelingt dieser Versuch nur mit verhältnissmässig frischen Flitssigkeiten, was ja auch verständlich ist, wenn man bedenkt, dass selbst concentrirte Fermentlösungen ihre Wirksamkeit verlieren, wenn sie längere Zeit stehen, ebenso muss in Betracht gezogen werden, welchen Temperaturen die betreffenden Macerationsflüssigkeiten ausgesetzt gewesen sind, denn es steht fest, dass hohe Temperaturen das Fibrinferment zerstören. So interessant es nun gewesen wäre, diese Ergebnisse weiter zu verfolgen, musste ich doch fürs erste davon Abstand nehmen, da es mir an Zeit gebrach.

In Bezug auf die Ergebnisse meiner Versuche will ich mich hier mit dem Gesagten begnügen, komme aber später im Zusammenhange mit den übrigen Versuchen noch einmal auf dieselben zurück.

\section{Reihe III A.}

Es könnte nun der Einwand erhoben werden, die in den vorstehenden Versuchen beobachteten Temperatursteigerungen seien bedingt nicht sowohl durch das injicirte Ferment, als vielmehr durch das mitinjicirte Wasser als solches und in der That lauten die in der Literatur über diesen Punkt enthaltenen Angaben derartig, dass man annehmen könnte, dieser Einwand sei gerechtfertigt.

Bergmann 1) sagt zum Schlusse einer Reihe von Controlversuchen mit Injectionen von Wasser ins Blut wörtlich Folgendes: „Mir scheint aus dem Angeführten zu folgen, dass nach Injection grosser Quantitäten von Wasser und kleiner Quantitäten reizender, d. h. den thierischen Organismus mehr oder weniger heftig angreifender Substanzen eine ganz analoge Temperatur-Alteration folgen

1) St. Petersburger med. Zeitschrift, Bd: XV. 1869. S. 84. 
kann, wie sie nach der Injection pyrogoner aus Fäulniss- und Entzündungsproducten stammender Flüssigkeiten jedesmal eintritt."

Auch Billroth ${ }^{1}$ ) hat diese Beobachtung bestätigen können und meint, eine Wasserinjection könnte unabhängig von der Quantität und unabhängig davon, ob erwärmtes oder nicht erwärmtes Wasser in Anwendung gezogen wird, unter Umständen eine Temperatursteigerung hervorrufen, es sei jedoch diese Temperatursteigerung eine ziemlich spät auftretende und schnell vorübergehende, etwa $1 \frac{1}{1} 2$ Stunden andauernde.

Meine nun folgenden Versuche scheinen indess nur in sehr beschränktem Maasse für diese Annahme zu sprechen.

Versuch 1.

\begin{tabular}{|c|c|c|c|c|}
\hline$\underset{\Xi}{E}$ & 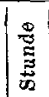 & 递 & 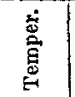 & Bemerkungen \\
\hline \multirow{6}{*}{$\begin{array}{c}23 / \mathrm{VI} . \\
1879 . \\
24 / \mathrm{VI} .\end{array}$} & & & \multirow{4}{*}{$\begin{array}{l}38,9 \\
39 \\
39,2 \\
39\end{array}$} & $\begin{array}{l}\text { Versuchsthier: Dieselbe Hündin aus dem Versuche } 1 \text { der } \\
\text { vorigen Versuchsreihe; das Thier hat in der Zwischen- } \\
\text { zeit um } 100 \text { Grm. an Gewicht zugenommen. }\end{array}$ \\
\hline & 9 & 10 & & \multirow{8}{*}{ Temperaturen vor dem Versuche. } \\
\hline & 12 & 30 & & \\
\hline & $\begin{array}{l}7 \\
9\end{array}$ & -30 & & \\
\hline & 2 & 40 & 39,1 & \\
\hline & 6 & 45 & 39,1 & \\
\hline \multirow[t]{2}{*}{ 25/VI. } & $\begin{array}{r}8 \\
11\end{array}$ & $\left|\begin{array}{l}55 \\
30\end{array}\right|$ & $\begin{array}{l}39,1 \\
39,3\end{array}$ & \\
\hline & 10 & 30 & 39,1 & \\
\hline \multirow[t]{14}{*}{$26 / \mathrm{VI}$. } & 10 & 10 & 39 & \\
\hline & 11 & 15 & 38,6 & Das Thier wird aufgebunden. \\
\hline & 11 & 25 & 38,6 & $\begin{array}{l}\text { Die Jugular. dextr. extern. ist freigelegt und die Canüle ein- } \\
\text { gebunden. Das Thier bleibt nun, um dieselben Verhält- } \\
\text { nisse zu wahren, wie im ersten Versuch, zu dem es ge- } \\
\text { dient hatte (mit der einzigen Abweichung, dass es hier } \\
\text { in Watte gehüllt wurde, wodurch offenbar die Abkühlung } \\
\text { vermieden werden konnte) liegen. }\end{array}$ \\
\hline & 3 & 10 & 38,6 & $\begin{array}{l}\text { Diese Temperatur hat das Thier die ganze Zeit hindurch } \\
\text { beibehalten, so zwar, dass dieselbe zwischen } 38,5 \text { und } \\
38,7 \text { schwankte. }\end{array}$ \\
\hline & 3 & 15 & 38,6 & $\begin{array}{l}\text { Injection von } 35 \mathrm{C} . \mathrm{Ctm} \text {. Aq. destill. beendet, die Injection } \\
\text { wird gut vertragen. Die Temperatur beginnt zu sinken. }\end{array}$ \\
\hline & 3 & 30 & 38,3 & Das Thier wird losgebunden. \\
\hline & 4 & 10 & 38,9 & Das Thier beginnt leicht zu zittern, ist aber sonst munter. \\
\hline & 4 & 35 & 38,7 & \\
\hline & & $\overline{30}$ & $\begin{array}{l}38,5 \\
38,5\end{array}$ & Status idem. \\
\hline & $\begin{array}{l}5 \\
6\end{array}$ & 30 & \begin{tabular}{|l|}
38,0 \\
38,6
\end{tabular} & Das Zittern hat aufgehört, das Thier ist vollständig wohl. \\
\hline & 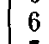 & 30 & 38,7 & \\
\hline & & - & 38,7 & Das Thier hat durch die Injection durchaus nicht gelitten, \\
\hline & 8 & $\begin{array}{l}40 \\
30\end{array}$ & $\begin{array}{l}38,8 \\
38,9\end{array}$ & es ist munter wie zuror, hat Appetit, normalen Stuhl. \\
\hline & 10 & - & 38,8 & \\
\hline
\end{tabular}

1) Langenbeck's Archiv. Bd. XIII. S. 637 u. 645 . 


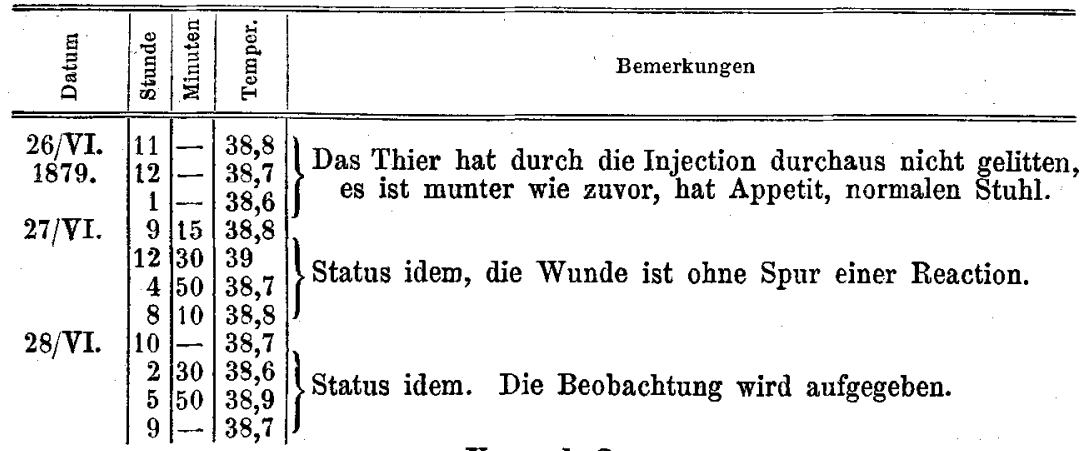

Versuch 2. $|\quad| \quad \begin{aligned} & \text { Versuchsthier: Junge Hündin, 3580 Grm. schwer, dieselbe } \\ & \text { wurde später am 13/VIII. 79. zum Versuche } 2 \text { der Reihe } \\ & \text { II gebraucht. }\end{aligned}$

25/VI.

Temperaturen vor dem Versuche.

$27 /$ VI. $\left.\quad \begin{array}{rr|r|r|r|}7 & 5 & 39 \\ 8 & 10 & 38,7 \\ 11 & 10 & 39 \\ 11 & 39\end{array}\right)$ $7 \begin{array}{lll}5 & 39\end{array}$ 1145 38,7

Das Thier wird aufgebunden.

Die Jugular. sinist. extern. ist freigelegt und die Canüle eingebunden.

12538 Injection von 42 C.-Ctm. Aq. destill. beendet, dieselbe wird gut vertragen.

Das Thier wird losgebunden, ist aber munter und läuft ohne das geringste Zeichen von Unwohlsein umher.

Status idem. Das Thier hat mit Appetit gefressen.

Das Thier ist beständig wohl und munter und es ist an demselben auch nicht die geringste Spur von Unwohlsein wahrnehmhar.

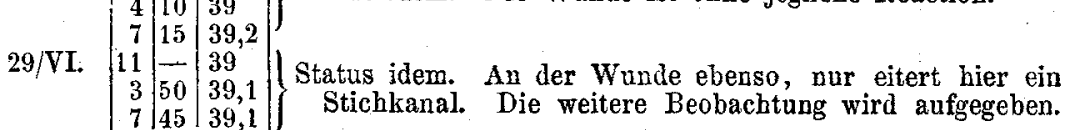

Versuch 3.

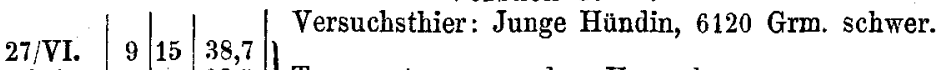

1879. $\left.\left|\begin{array}{ll|l|l|l|l}3 & 15 & 38,5 \\ 7 & 45 & 39\end{array}\right|\right\}$ Temperaturen vor dem Versuche. 
Ein Beitrag zur Lehre von der Thrombosis und vom Fieber.

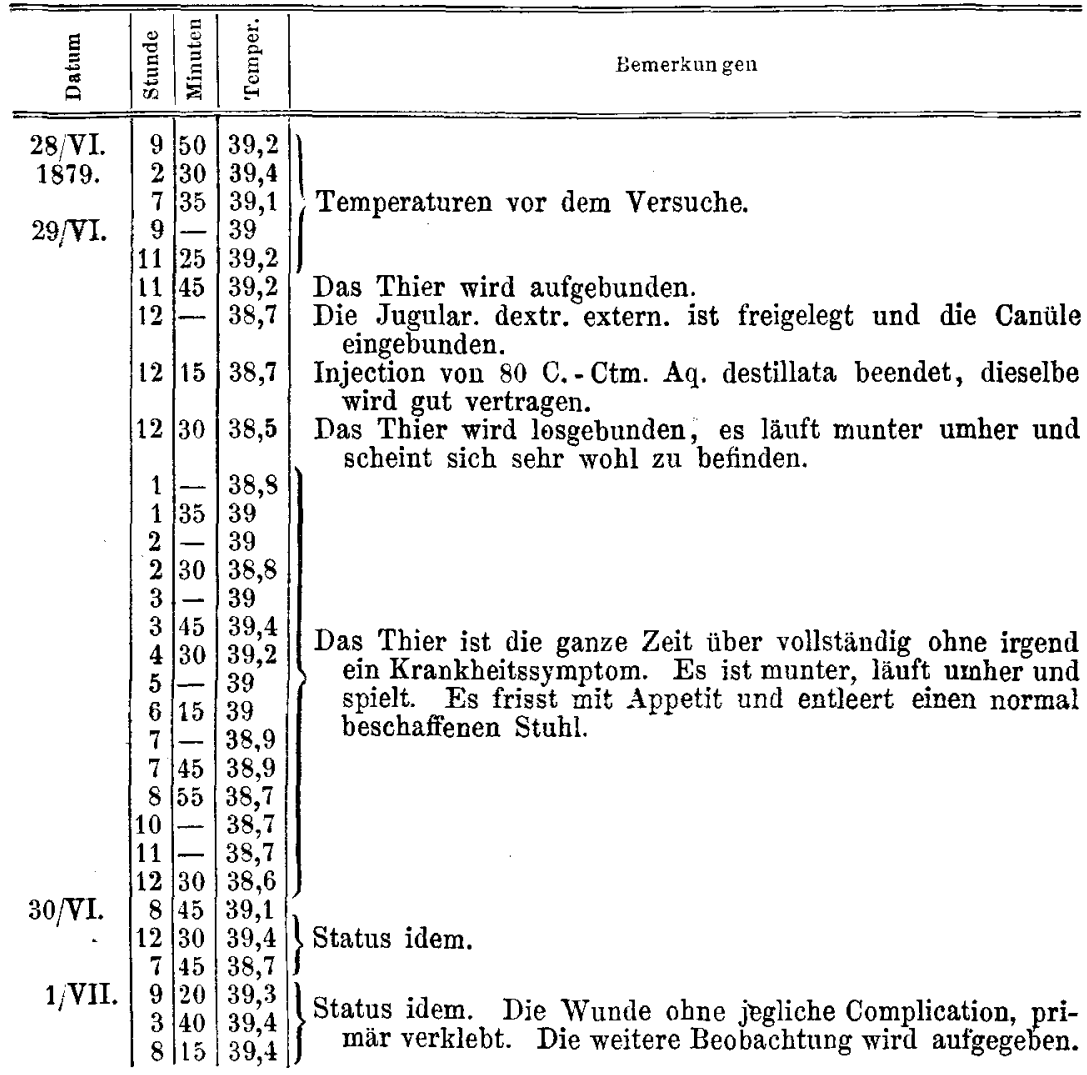

\section{Versuch 4.}

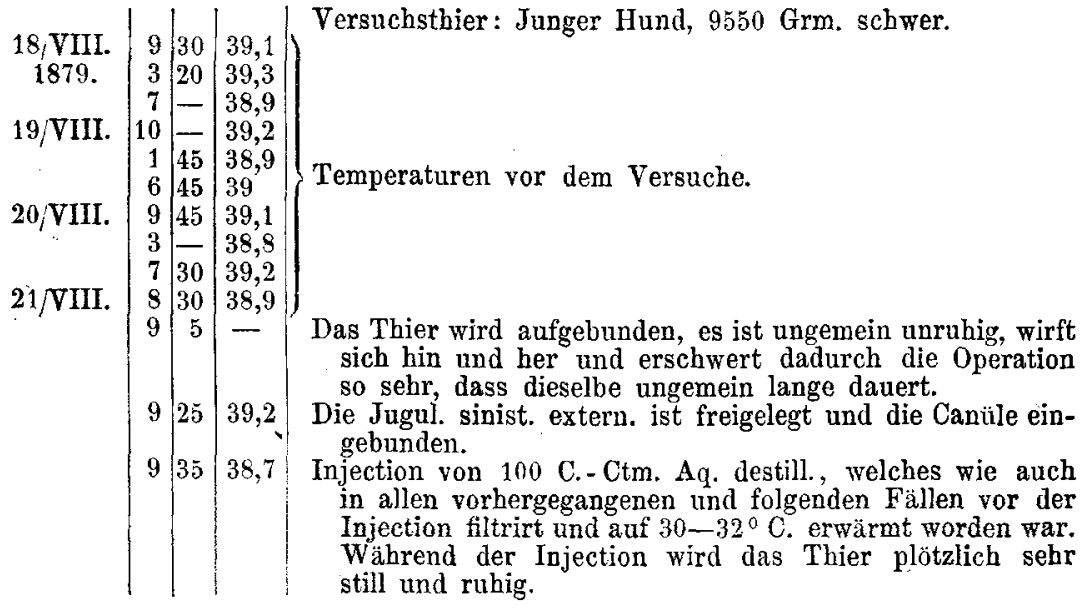




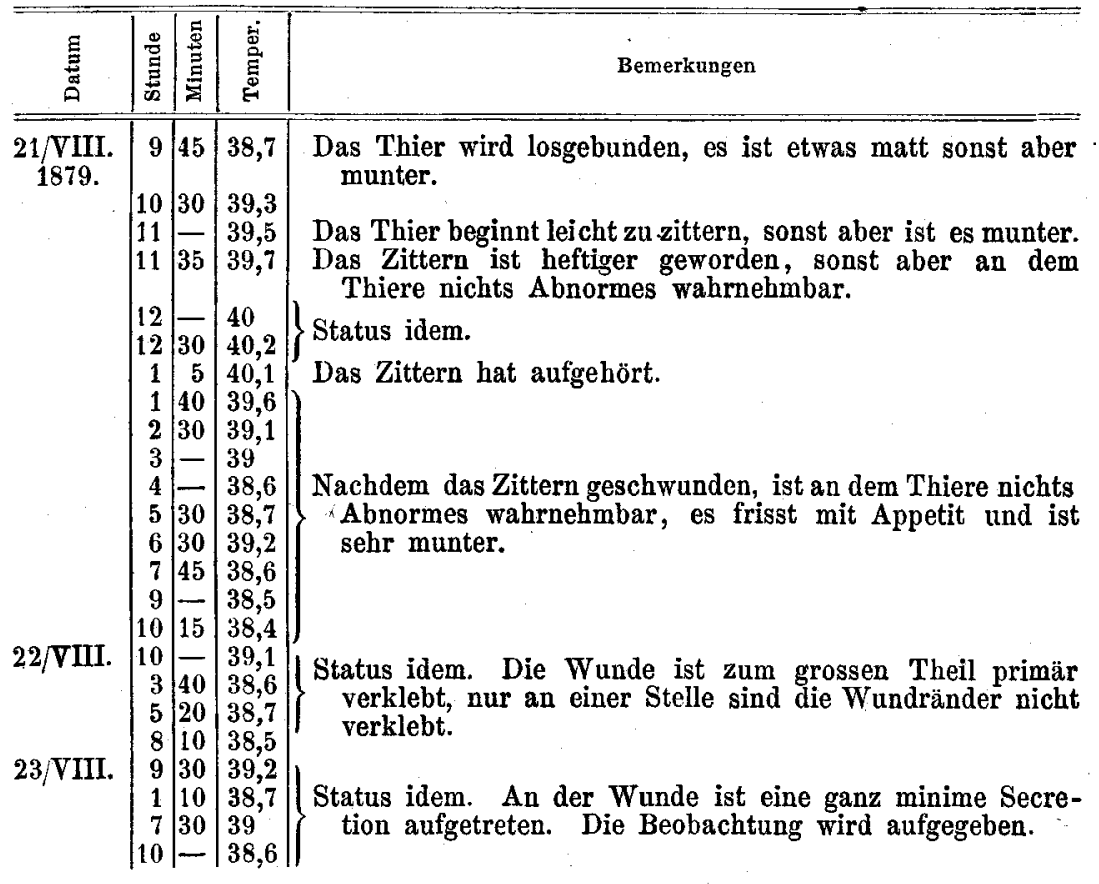

\section{Versuch 5.}

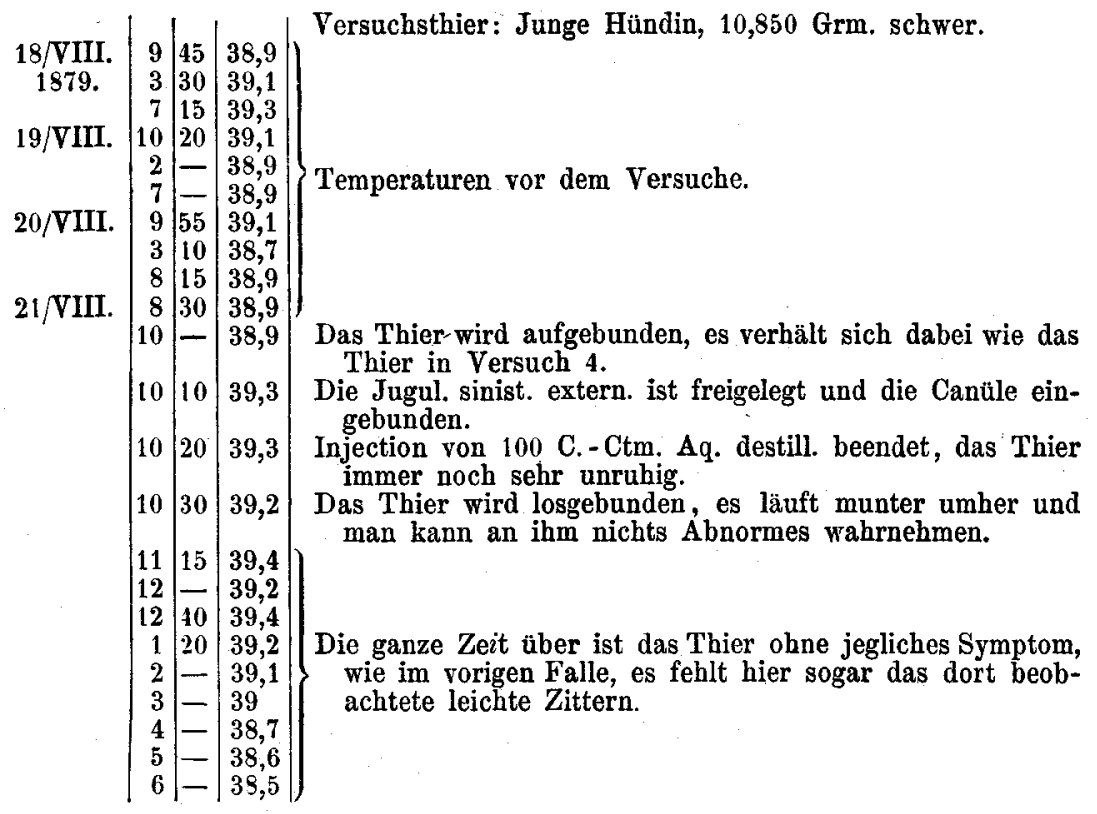


Fin Beitrag zur Lehre von der Thrombosis und vom Fieber.

\begin{tabular}{|c|c|c|c|c|}
\hline 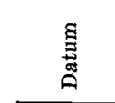 & 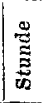 & | & 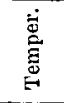 & Bemerkungen \\
\hline 21/VIII. & 7 & 30 & 38,4 & \\
\hline 1879. & $\left|\begin{array}{r}9 \\
10\end{array}\right|$ & $\overline{30}$ & $\begin{array}{l}38,4 \\
38,5\end{array}$ & Das Thier frisst mit Appetit und ist gesund. \\
\hline $22 /$ VIII. & 9 & 50 & 38,7 & \\
\hline & $\begin{array}{l}3 \\
5 \\
8\end{array}$ & $\begin{array}{l}20 \\
30 \\
20\end{array}$ & $\begin{array}{l}38,7 \\
38,9 \\
38,6\end{array}$ & Status idem. \\
\hline $23 /$ VIIL. & $\begin{array}{l}9 \\
1 \\
7 \\
9\end{array}$ & $\begin{array}{l}\frac{40}{15} \\
30\end{array}$ & $\begin{array}{l}38,8 \\
39 \\
39,4 \\
39\end{array}$ & $\begin{array}{l}\text { Status idem. Von Seiten der Wunde keine Complication. } \\
\text { Die Beobachtung wird aufgegeben. }\end{array}$ \\
\hline
\end{tabular}

\section{Versuch 6.}

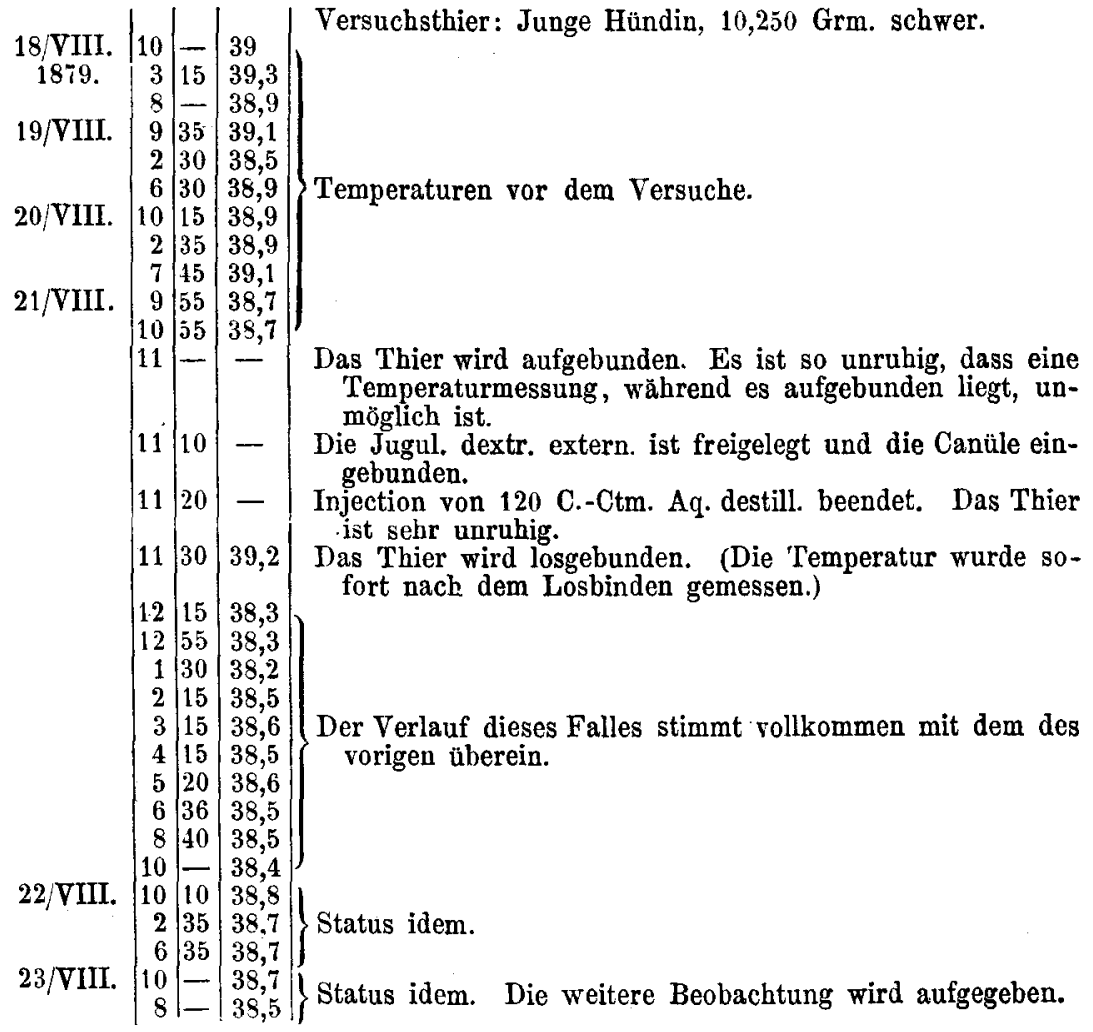

Versuch 7.

$\left.\begin{array}{c|c|c|c|c}\text { 15/IX. } & 9 & 30 & 39,1 \\ 1879 . & 3 & 40 & 39,2 \\ 7 & 50 & 38,9\end{array}\right\}$ Tersuchsthier: Derselbe Hund aus Versuch 4 dieser Reihe. 


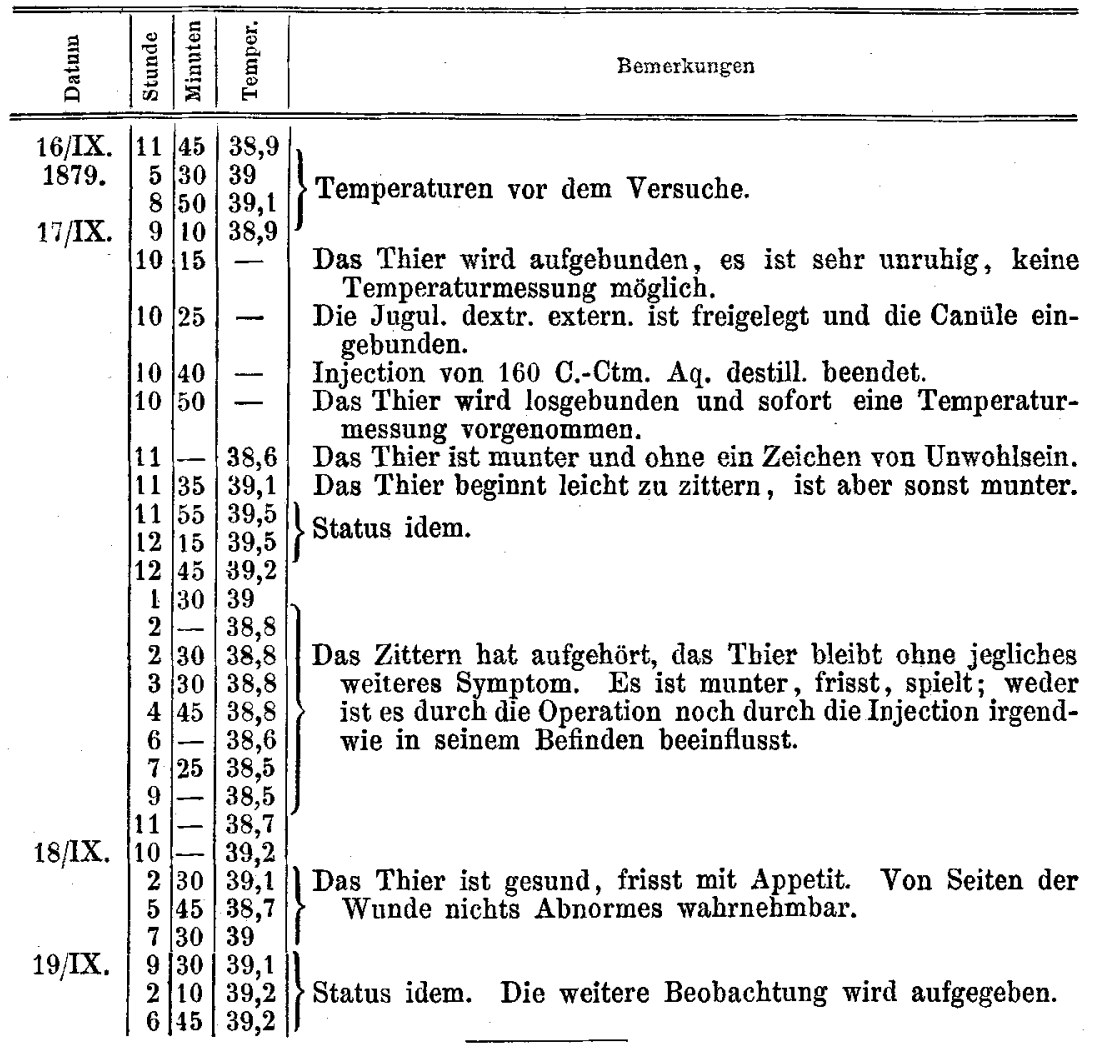

Fassen wir die Ergebnisse der letzten Versuchsreihe zusammen, so müssen wir zugestehen, dass ein grosser Unterschied zwischen ihnen und denen der Reihe II besteht, denn während dort in 12 Versuchen jedesmal eine beträchtliche Temperatursteigerung verbunden mit einem ganz specifischen Symptomencomplex auftritt, tritt uns hier nur einmal unter 7 Fällen eine schnell voribergehende, verhältnissmässig leichte Temperatursteigerung ohne jegliches begleitende Symptom, mit Ausnahme eines leichten ebenfalls nur kurze Zeit dauernden Zitterns, entgegen. In den übrigen 6 Fällen übersteigt die Temperatur nach der Injection von Wasser kaum die früher beobachteten Normaltemperaturen. Diese Thatsachen sprechen, wie ich glaube, sehr auffallend für die Specificität der Fibrinfermentwirkung.

\section{Reihe IIIB.}

Es schien mir nun sowohl als weitere Controle fur meine Versuche, als auch von anderen Gesichtspunkten aus, interessant zu 
sein, Injectionen mit Flissigkeiten anzustellen, welche ganz ebenso wie meine Fermentlösungen gewonnen waren, nur dass als Material zur Darstellung derselben nicht Blutserum oder defibrinirtes Blut benutzt wurde, sondern das circulirende, also fermentfreie Blut selbst, - Lösungen demnach, welche alle Bestandtheile der Fermentlösungen enthalten, nur eben nicht das Ferment. Solche Lösungen erhielt ich in bekannter Weise, indem ich das Rinderblut direct in Alkohol fliessen liess und das Coagulum ganz ebenso behandelte, wie bei Darstellung wirksamer Lösungen. Die betreffenden Wasserextracte verhielten sich, wie ich bestätigen kann, absolut unwirksam gegen verdïnntes „Salzplasma", ermangelten demnach jedes Fermentgehaltes. Ein gemessenes Quantum einer solchen Lösung hinterliess einen Gesammtrïckstand von $0,448 \mathrm{pCt}$. Weiterhin werde ich diese Lösungen, welche natürlich gleichfalls roth gefärbt waren, als Lösungen $C$ bezeichnen.

$\mathrm{Zu}$ meiner Verwunderung ergab gleich der erste Versuch, dass die Injection eines solchen fermentfreien Blutextractes in das Blut ganz denselben Symptomencomplex hervorrief, wie ich ihn nach Fermentinjection beobachtet hatte. Namentlich stieg die Temperatur rasch zu einer bedeutenden Höhe an, erreichte nach 3 Stunden ihr Maximum $\left(40,9^{\circ}\right.$ C.), um dann ebenso rasch wieder zur Norm zurückzusinken.

Wie soll man sich dieses Ergebniss erklären?

Eine Temperaturerhöhung des Organismus mag alle möglichen Ursachen haben, meine bis hierher angeführten Versuche haben, glaube ich, ergeben, dass sie unter anderem auch die Folge der Anwesenheit von Fibrinferment im Blute ist. Sollte nun nicht die völlige Uebereinstimmung des Symptomencomplexes an die Möglichkeit denken lassen, dass auch hier Fermentwirkungen im Blute stattfanden, obgleich das injicirte Extract völlig fermentfrei war?

Bei näherer Ueberlegung ergab sich mir folgende Alternative. Erstens weiss man von einigen thierischen Fermenten, dass sie ursprtinglich in einem gebundenen, unwirksamen Zustande als sogenannte "Zymogene" in den betreffenden Zellen enthalten sind und dass sie unter geeigneten Umständen erst durch eine Spaltung frei und wirksam werden. Auch im circulirenden Blute ist normal, wie bekannt, kein freies Fibrinferment enthalten, weder in der Blutflüssigkeit, noch in den farblosen Blutkörperchen, aber in den letzteren als der Bildungsstätte des Ferments muss doch der Mutterstoff desselben entbalten sein. Sollte dieser Stoff nun nicht ein "Zymogen" darstellen, welches bei Fällung des Blutes mit Alkohol vom Coa- 
gulum eingeschlossen wird, dann als solches, also in unwirksamer Gestalt, in das Wasserextract übergeht, um endlich bei Injection in das Blut eines lebenden Thieres, und zwar in die Zwischenzellenflüssigkeit, in Verhältnisse zu gerathen, welche die Spaltung und somit die Entstehung freien Fermentes im Blute aus dem injicirten „Zymogen" herbeiführen? Zweitens erschien es aber auch denkbar, dass das injicirte fermentfreie Wasserextract durch irgend einen seiner Bestandtheile (abgesehen vom immerhin fraglichen "Zymogen") etwa durch seinen Wassergehalt eine Störung im Blute bewirkte, deren Folge Entwicklung von Fibrinferment aus den beztiglichen Bestandtheilen des Blutes selbst war. Ein mal unter sieben Versuchen hat wenigstens auch die Injection von destillirtem Wasser eine Temperatursteigerung hervorgerufen und wenn dieses, wie wir sehen werden, jedesmal eintrat nach Injection der Wasserextracte aus fermentfreiem Blutpulver, so waren in denselben ausser dem Wasser noch andere Bestandtheile vorhanden, welche möglicher Weise noch störender wirkten, als das Wasser an sich.

Zur Erklärung der offenbar im Vergleich mit dem Wasser intensivern Wirkung der letzterwähnten fermentfreien Wasserextracte bleibt aber schliesslich auch noch die Annahme tibrig, dass dieselbe auf beiden Umständen beruht, also zugleich das Resultat ist einer Zymogenspaltung und der Störung im Blute durch andere Bestandtheile des Extractes. Beide Erklärungsversuche kommen demnach auf die Annahme heraus, dass nach Injection des fermentfreien Wasserextractes freies Ferment im Blute auftritt und diese Annahme zu priifen war meine nächste Aufgabe.

$\mathrm{Zu}$ diesem Behufe öffnete ich gleich im ersten Versuche, 3 Stunden nach der Injection, als die Temperatur auf 40,9 ${ }^{\circ} \mathrm{C}$. gestiegen war, die Vena saphena und liess eine kleine Menge Blut in Alkohol fliessen; das Coagulum wurde alsdann in gewöhnlicher Weise behandelt und das Wasserextract desselben mit "Salzplasma" auf seinen Fermentgehalt geprüft. Ebenso verfuhr ich in zwei weiteren hierhergehörigen Versuchen, bei welchen ganz derselbe Symptomencomplex hervortrat, wie in dem soeben erwähnten. Ich band aber bei den letzteren in das periphere Ende der Vena jugul. eine kleine Glascanüle behufs der nöthigen Blutabnahmen ein, welche bis zum nächsten Morgen liegen blieb. Durch dieselbe fing ich mehreremal kleine Blutproben (10-15 C.-Ctm.) in Alkohol auf und zwar das erste Mal unmittelbar vor der Injection (um den absoluten Fermentmangel des gesunden Blutes zu constatiren), das zweite Mal 5-10 Minuten nach der Injection, dann noch einigemal in Intervallen von ein paar Stunden 
und das letzte Mal am folgenden Morgen (beide Injectionen fanden am Nachmittag statt). Nach jeder Blutabnahmè wurde die Glasröhre ausgewaschen; es fand weder in ihr, noch in der Vene selbst bis zum Abend eine Gerinnselbildung statt, erst am Abend und am folgenden Morgen hatte sich oberhalb der abgesperrten Stelle in der Vene ein kleines Gerinnsel gebildet, dasselbe wurde natürlich durch Streichen entfernt, bevor die Blutabnahme stattfand.

Die nun folgenden Versuche geben die Beobachtungsresultate, sofern sie die Thiere. selbst betreffen.

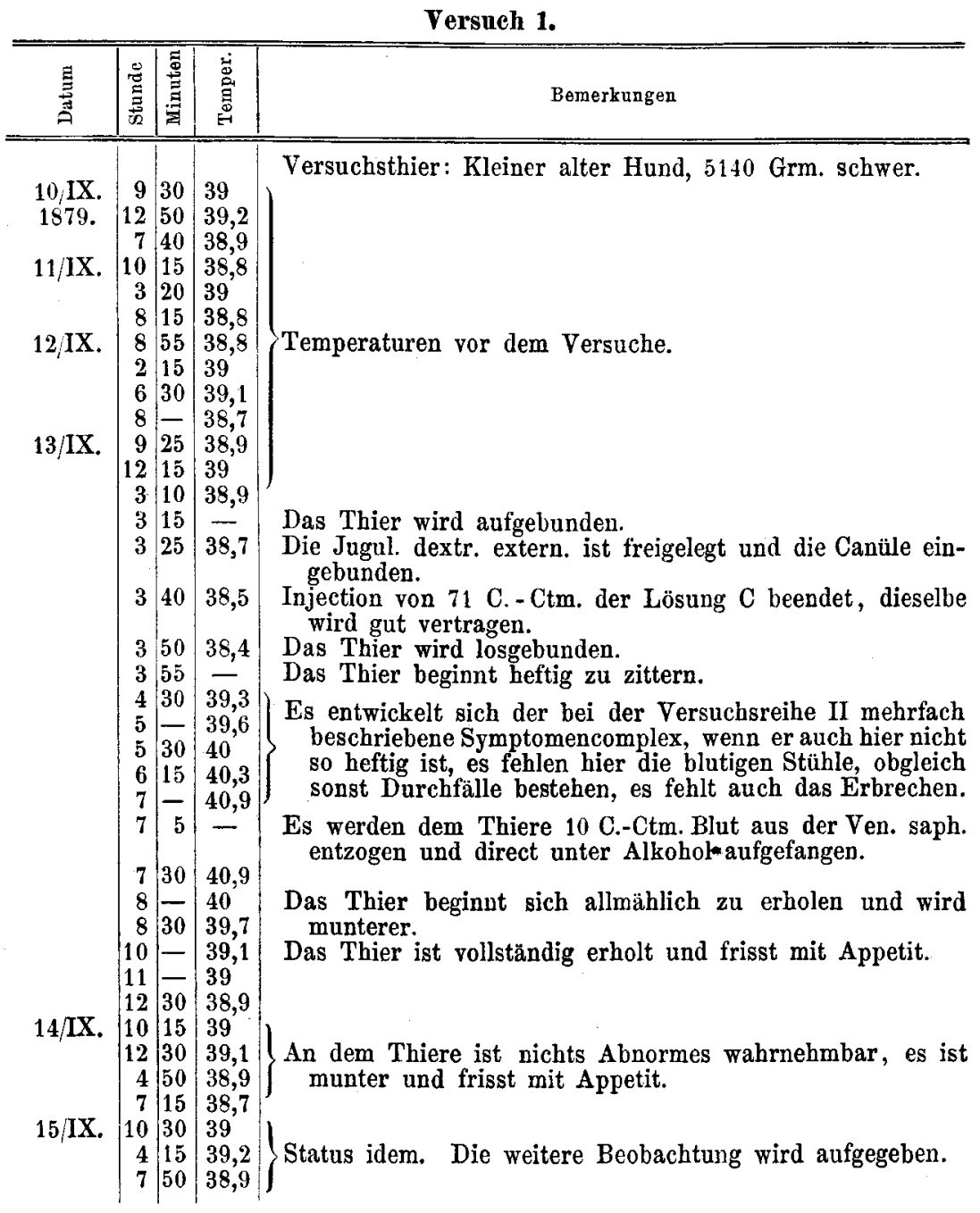


Versuch 2.

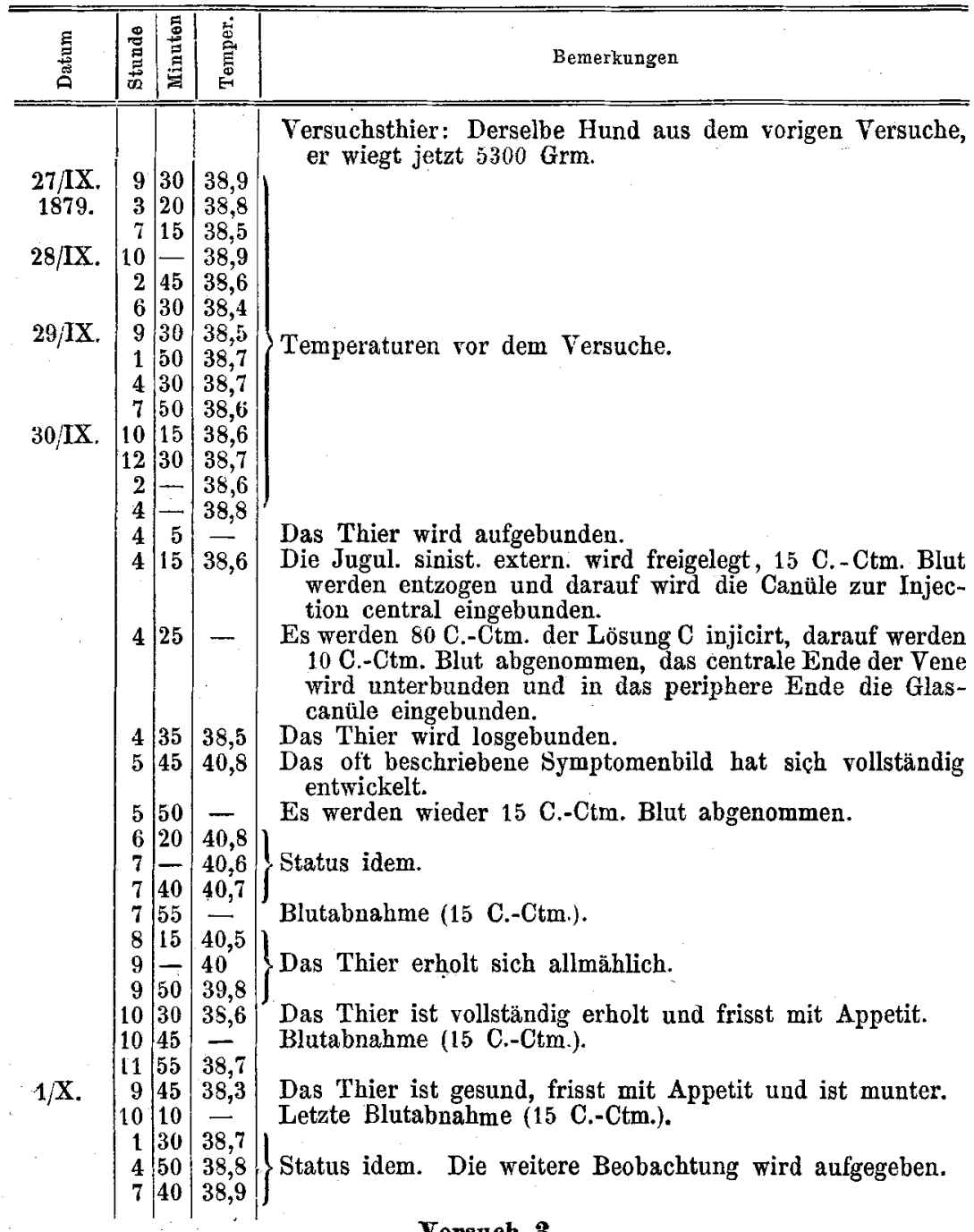

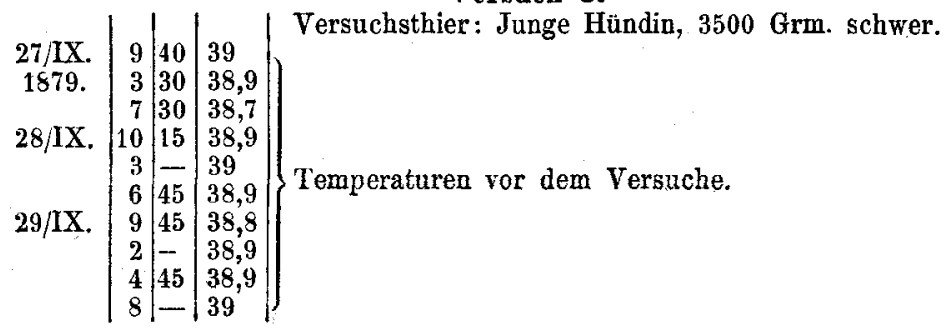


Ein Beitrag zur Lehre von der Thrombosis und vom Fieber.

\begin{tabular}{|c|c|c|c|c|}
\hline 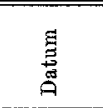 & & 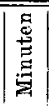 & 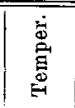 & Bemerkungen \\
\hline $\begin{array}{c}\text { 30/IX. } \\
1879 .\end{array}$ & $\mid \begin{array}{r}10 \\
12 \\
2 \\
4 \\
4 \\
5\end{array}$ & $\mid \begin{array}{c}55 \\
30 \\
- \\
5 \\
30\end{array}$ & $\begin{array}{l}\overline{-} \\
40,3 \\
40,3 \\
40 \\
-\overline{39,5} \\
39 \\
38,7 \\
38,7 \\
\\
38,8 \\
38,7 \\
38,8\end{array}$ & $\begin{array}{l}\text { Temperaturen vor dem Versuche. } \\
\text { Das Thier wird aufgebunden. } \\
\text { Die Jugul. dextr. extern. wird freigelegt, ans derselben etwa } \\
\text { 15 C. - Ctm. Blut entzogen, darauf wird die Canüle zur } \\
\text { Injection central eingebunden, } \\
\text { Injection von 50 C.-Ctm. der Lösung C beendet, es werden } \\
\text { 15 C.-Ctm. Blut entzogen. } \\
\text { Das Thier wird losgebunden; es ist munter, entleert aber } \\
\text { einen breiigen Stuhl. } \\
\text { Es entwickelt sich nun in kurzer Zeit das gewöhnliche Bild, } \\
\text { welches jeder Injection von ferment h altig en Flüssig- } \\
\text { keiten folgt. } \\
\text { Blutabnahme (15 C.-Ctm.). } \\
\text { Das Thier erbricht. } \\
\text { Status idem. } \\
\text { Das Thier ist sehr matt, es leidet an sehr quälenden Te- } \\
\text { nesmen, die Respiration ist sehr beschleunigt und er- } \\
\text { schwert, es werden dünnflüssige, schwarze Stühle entleert. } \\
\text { Das Thier erbricht. } \\
\text { Blutabnahme (15 C.-Ctm.). } \\
\text { Status idem. } \\
\text { Blutabnahme (15 C.-Ctm.). } \\
\text { Das Thier ist etwas munterer, scheint sich etwas erholt } \\
\text { zu haben. } \\
\text { Das Thier hat sich vollständig erholt, frisst mit Appetit } \\
\text { und ist sehr munter. } \\
\text { Das Thier ist sehr munter, es ist nichts Abnormes an ihm } \\
\text { wahrnehmbar, es frisst mit Appetit. } \\
\text { Blutabnahme (15 C.-Ctm.). } \\
\text {, } \\
\text { Status idem. Die weitere Beobachtung wird aufgegeben. }\end{array}$ \\
\hline
\end{tabular}

Die vorstehende Versuchsreihe ergibt demnach, dass die Injection von Wasserextracten aus fermentfreien Blutpulvern denselben Symptomencomplex hervorruft wie die Injection einer Fermentlösung. Die während der Versuche abgenommenen und in Alkohol aufgefangenen Blutproben wurden, nachdem sie 5 Tage unter Alkohol gestanden, abfiltrirt, das Coagulum getrocknet, pulverisirt, mit Wasser im Verhältniss von 1:4 extrahirt und die Extracte zu verdünntem "Salzplasma" gesetzt und zwar im Verbältniss von 1 Theil des letzteren zu 6 Theilen Wasser und 2 Theilen Extract. Das Resultat war kurz folgendes:

Die beiden vor der Injection abgenommenen Blutproben ergaben ein vollig unwirksames, also ferment- 
freies Wasserextract, dagegen gerannen alle tibrigen Mischungen; alle Wasserextracte, welche aus den nach der Injection abgenommenen Blutproben stammten, waren also fermenthaltig.

Ferner zeigte sich in Versuch 2 sowohl, als in Versuch 3, dass das der zweiten fast unmittelbar nach der Injection abgenommenen Blutprobe entsprechende Wasserextract am energischsten wirkte, indem es die Gerinnung in 8-10 Minuten herbeiführte und dass die folgenden Extracte der Reihe nach immer schwächer und langsamer wirkten, so dass das am Morgen nach der Injection abgenommene Blut ein Extract lieferte, welches im verdünnten "Salzplasma" fast gar keine Gerinnselbildung einleitete.

Bedenkt man nun aber, dass der Organismus über Kräfte disponirt, durch welche er das Fibrinferment beständig zerstört, so ist der durch das zweite in beiden Versuchen in $8-10$ Minuten wirkende Wasserextract dargestellte Fermentgehalt des Blutes als ein auffallend hoher zu bezeichnen.

Das unzweifelhafte Resultat dieser Versuche ist also, dass nach Injection der uns hier beschäftigenden fermentfreien Flüssigkeiten plötzlich das Fibrinferment in beträchtlichen Mengen im eirculirenden Blute auftritt, um alsdann, gerade wie das als solches injicirte Ferment, aus demselben allmählich wieder zu verschwinden. Das Vorhandensein des Ferments im Blute ist aber, gleichgiltig, ob dasselbe durch Injection dorthin gelangte, oder sich erst dort entwickelte, von ganz identischen Störungen im körperlichen Wohlbefinden des Thieres begleitet. Sollte diese Uebereinstimmung eine rein zufällige sein und nicht vielmehr auf einen tieferen Zusammenhang hinweisen?

Wie aus den Tabellen hervorgeht, fällt aber das Temperaturmaximum nicht mit dem Maximum des Fermentgehaltes im Blute zusammen, sondern tritt erst verhältnissmässig viel später auf; dasselbe gilt aber ebenso auch von denjenigen Versuchen, in welchen fermenthaltige Flïssigkeiten in das Blut injicirt wurden. In diesen Versuchen trat nämlich das Maximum der Temperatursteigerung frühestens 1 Stunde 22 Minuten und spätestens 3 Stunden 35 Minuten, im Mittel aller Versuche 2 Stunden 25 Minuten nach der Injection ein, also zu einer Zeit, wo, wie Jakowicki gezeigt hat, bereits der grösste Theil des injicirten Fermentes eliminirt sein musste.

Leider gestattete mir meine Zeit nicht, eine neue in Wasserinjectionen bestehende Versuchsreihe zu beginnen, um nach der bereits angegebenen Methode die Frage zur Entscheidung zu bringen, ob das Wasser an sich mit Fermententwicklung einhergehende Stö- 
rungen im Blute herbeiführen kann. Der Umstand, dass unter 7 Versuchen mit Wasserinjection ins Blut doch e in mal eine, wenn auch leichte Temperaturerhöhung beobachtet wurde, scheint einen Anhalt zu bieten für die Annahme einer solchen Wirkung des injicirten Wassers, während andererseits das sechsmalige Fehlen der Temperaturerhöhung dahin gedeutet werden könnte, dass das Wasser in dieser Hinsicht nur schwach wirkt und deshalb wohl auch nur, wenn nicht zufällig die Widerstandsfähigkeit des Organismus im Augenblicke gerade eine geringere ist, von der Injection grosser Wassermengen ein sicheres Resultat erwartet werden dürfte.

In Betreff der Frage, in welcher Weise das factische Auftreten von Fibrinferment im Blute nach Injection fermentfreier Extracte zu erklären sei, muss ich mich unter solchen Umständen auf die Eingangs dieser Versuchsreihe angedeutete Alternative beschränken.

\section{Reihe IIIC.}

Nachdem ich mich bis soweit mit der Wirkung des Fibrinferments auf den Organismus beschäftigt, schien es mir in Betreff des Wundfiebers, soll man anders dasselbe in irgend einen Zusammenhang mit diesem Ferment bringen dürfen, nothwendig zu sein, den Einfluss der Carbolsäure auf das letztere zu studiren.

Die erste Frage war, ob die Carbolsäure im Stande sei die Wirkung des Fibrinferments auf das Gerinnungssubstrat zu hindern. Zur Entscheidung dieser Frage stellte ich mir die gewöhnlichen achtfach verdünten Gerinnungsmischungen her unter Zusatz von steigenden Mengen 5 procentiger Carbolsäurelösung bei entsprechender Verminderung des Wasserzusatzes. In der neun Vol. betragenden Mischung stieg ich von 1/2 Vol. Carbolsäure auf 1, 11/2, 2, 21/2 Vol. u. s. w. Nur die mit $1 / 2,1$ und $1 \frac{1 / 2}{2}$ Vol. Carbolsäure versetzten Mischungen konnten beobachtet werden, weil grössere Mengen Carbolsäure mächtige Albumingerinnungen bewirkten, durch welche ein Urtbeil uber eine etwa stattfindende Faserstoffgerinnung ebenso unmöglich gemacht wurde, wie bei raschem Aufkochen von Blutplasma oder einer künstlichen Gerinnungsmischung.

Das Resultat dieser Versuche war, dass der Zusatz von 1/2 Vol. Carbolsäure die Gerinnung bedeutend verlangsamte, dass aber der Zusatz von 1 resp. 1//2 Vol. sie vollständig aufzuheben schien, da selbst nach 24 Stunden nichts weiter als eine staubförmige, einen leichten Bodensatz bildende Trübung bemerkt werden konnte, welche Trübung auch eintrat, wenn man blos verdtinntes ,Salzplasma" mit Carbolsäure mischte, mithin wohl als eine schwache durch die letz- 
tere bewirkte Albumingerinnung anzusehen ist. Ich bemerke hierzu, dass ja bekanntlich ein Zusatz von $\mathbf{3}-\mathbf{5}$ procentiger Carbolsäure in allen Eiweisslösungen derartige allmählich auftretende Niederschläge bewirkt.

Nun entstand aber die Frage: Hemmt dié Carbolsäure, wie etwa die Kälte, die neutralen Alkalisalze, blos den Vorgang der Gerinnung, ohne das Ferment selbst anzugreifen, oder beruht ihre Wirkung darauf, dass sie dasselbe mehr weniger vollkommen zerstört? Wie man sieht, war es zur Entscheidung dieser Frage nöthig, die Carbolsäure zuvörderst eine Zeit lang auf das Fibrinferment allein einwirken zu lassen und sie dann wieder zu beseitigen, so dass in die nun erst herzustellende Gerinnungsmischung keine Carbolsäure hineinkam. Zu diesem Behufe konnte ich die Carbolsäure nicht einer reinen, wässrigen Fermentlösung zusetzen, weil ich sie nicht anders aus ihr wieder fortzuschaffen wusste, als durch Verdunstung, durch welche auch das Fibrinferment zerstört oder wenigstens in 'hohem Grade abgeschwächt worden wäre, ein Umstand, auf den man hätte Rücksicht nehmen mitssen, falls die Gerinnungsmischungen nicht gerannen.

Ich konnte aber meinen Zweck auf folgende Weise erreichen. Gleiche Mengen Rinderblutserum wurden steigend mit so viel 5 proc. Carbolsäurelösung versetzt, dass der Gehalt an reiner Carbolsäure resp. $1 / 2,1,1^{1 / 2}$ und 2 pCt. betrug, eine fünfte Portion des Serums blieb ohne Carbolsäurezusatz. Alle fünf Portionen wurden nach etwa 24 Stunden, nachdem sie an einem kühlen Orte gestanden hatten, mit dem fünfzehnfachen Vol. Alkohol gefällt. Nach 14 Tagen wurde abfiltrirt und die Coagula der mit Carbolsäure versetzten Portionen noch einigemale mit starkem Alkohol ausgewaschen. In der That wurde hierdurch der vom Coagulum noch zurïckgehaltene Carbolsäurerest so vollständig entfernt, dass weder dieses selbst, noch das Wasserextract desselben den geringsten Carbolsäuregeruch zeigten. Ein Theil des mit 1/2 proc. Carbolsäure versetzten Serums war übrigens schon nach einer halben Stunde mit Alkohol coagulirt worden. Die Prüfung der aus diesen Serumeoagulis gewonnenen Wasserextracte mittelst der Reactionsflissigkeit lehrte, dass schon eine halbstiundige Einwirkung $1 / 2$ proc. Carbolsäure auf das Rinderblutserum die Wirksamkeit des Ferments in hohem Grade abgeschwächt hatte. Eine 24 stündige Einwirkung von $1 / 2-, 1$ - und 2 proc. Carbolsäure bedingte aber völlige Unwirksamkeit der Wasserextracte, wenn ich die gewöhnliche Gerinnungsmischung (ein Theil "Salzplasma", ein Theil Wasserextract, sieben Theile Wasser) herstellte. Nur wenn 
ich das "Salzplasma" ohne weiteren Wasserzusatz mit acht Theilen Wasserextract mischte, trat erst nach 6-8 Stunden eine äusserst geringe, flockige, leicht zerfallende Gerinnung ein, während das Wasserextract aus dem nicht mit Carbolsäure behandelten Serum in dem gewöhnlichen Verhältniss zugesetzt in wenigen Augenblicken eine ganz vollkommene Gerinnung herbeiführte. Nach Einwirkung von 2 proc. Carbolsäure war tibrigens auch diese schwache Wirksamkeit des Wasserextracts nicht mehr bemerkbar.

Aus diesen Ergebnissen wïrde zunächst zu folgern sein, dass eine genügende Menge Carbolsäure, wenn sie hinreichend lange auf das im Blutserum angehäufte freie Fibrinferment einwirkt, dasselbe vollkommen unwirksam macht, resp. zerstört, speciell dass der $\mathrm{Zu}$ satz von 1 proc. Carbolsäure im Laufe von 24 Stunden den Fermentgehalt des Serums so weit reducirt, dass kaum in Betracht kommende Spuren desselben zurïckbleiben.

Diese Folgerung bezieht sich aber nur auf das im Blutserum enthaltene freie Ferment; lässt man die Carbolsäure auf das genuine, ungeronnene Blut einwirken, in welchem das Ferment noch in unwirksamem gebundenem Zustande existirt, d. h. also, lässt man die Fermententwicklung in dem unmittelbar aus der Ader kommenden Blute bei Gegenwart von Carbolsäure stattfinden, oder, anders ausgedrückt, lässt man das Blut unter dem Einfluss von Carbolsäure gerinnen, so ist das Resultat ein sehr eigenthümliches. Ich stellte diese Versuche in der Weise an, dass ich eine grössere Menge Pferdeblut in einem von einer starken Kältemischung umgebenen Gefässe auffing und dann mit der Pipette gemessene Mengen des gekühlten Plasmas in eine Reihe bereit stehender Gläser brachte, welche abgemessene Mengen von Carbolsäure enthielten, so zwar, dass der Gehalt an Carbolsäure in der Mischung $1 / 2,1,1{ }^{1 / 2}, 2,21_{1 / 2}^{1}, 3,5,7$ und 10 pCt. betrug; zur Controle blieb der Rest des Plasmas ohne Carbolsäurezusatz. Die Präparate wurden alsdann gewöhnlicher Zimmertemperatur ausgesetzt und die Gerinnungsgeschwindigkeiten beobachtet und mit derjenigen der Controlprobe verglichen. Ich fand, dass $1 / 2$ proc. Carbolsäure die Gerinnung nicht bemerkbar beeinflusste, 1 proc. verzögerte sie sehr deutlich, $1 \frac{1 / 2}{1}$ proc. noch mehr, 2- und $2^{1 / 2}$ proc. beschleunigten sie plötzlich ausserordentlich, 3 und mehr Procent Carbolsäure riefen starke flockige Eiweissgerinnungen hervor, welche zunächst ein Urtheil iuber den etwaigen Einfluss der Säure auf die Faserstoffgerinnung unmöglich machten. Wie aber aus dem sogleich Folgenden hervorgehen wird, fand jedoch in den letzteren Präparaten ibberhaupt keine Faserstoff- sondern nur Eiweissgerin- 
nung statt, weil von der Grenze von 3 proc. Carbolsäure an überhaupt gar kein Fibrinferment im Blute auftritt. Zur weiteren Bestätigung dieser Ergebnisse coagulirte ich nämlich etwa 10 Stunden nach dem Aderlass sämmtliche Präparate mit dem zehnfachen Vol. Alkohol und verfuhr wie gewöhnlich bei Darstellung meiner Fermentlösungen. Auch die Controlprobe war nach beendeter Gerinnung in dieser Weise behandelt worden. Ich wollte so ermitteln, ob die beobachtete Verzögerung der Gerinnung mit verminderter, die Beschleunigung derselben aber mit vermehrter Fermententwicklung Hand in Hand ginge, beides durch den Einfluss verschiedener Mengen von Carbolsäure bedingt und beides erkennbar durch eine herabgesetzte resp. gesteigerte Wirksamkeit der bezüglichen Wasserextracte auf das verdünnte "Salzplasma". Die erhaltenen Wasserextracte wurden demnach in Betreff ihres Fermentgehalts wie gewöhnlich mit "Salzplasma" geprüft. Ich will die Mischungen der Kürze wegen in aufsteigender Reihe (mit Bezugnahme auf den Carbolsäurezusatz zum Plasma) mit No. 1, No. 2, No. 3 u. s. w. bezeichnen.!

Ich fand Folgendes:

Die mit Wasserextract aus der Controlblutprobe hergestellte Salzplasmamischung gerann in 12 Minuten.

No. 1 ( $1 / 2$ proc. Carbolsäure) zeigte eine kaum bemerkbare Verzögerung.

No. 2 (1 proc. Carbolsäure) zeigte eine sehr deutliche Verzögerung.

No. 3 (11/2 proc. Carbolsäure) noch mehr.

No. 4 (2proc. Carbolsäure) bewirkte Gerinnung in 2 Minuten.

No. 5 (21/2 proc. Carbolsäure) bewirkte Gerinnung in $1 \frac{1}{2}$ Minuten.

No. 6 (3 proc. Carbolsäure) und alle folgenden Nummern bewirkten gar keine Gerinnung.

In Bezug auf die Controlmischung möchte ich darauf aufmerksam machen, dass, sowie das Pferdeblut selbst langsam gerinnt, auch die aus dem Serum desselben dargestellten Fermentlösungen sehr langsam wirken. Construirt man sich für das angeführte Ergebniss eine die Energie der Fermententwicklung im Blute, bei gleichmässig steigendem Carbolsäurezusatz, darstellende Curve, deren Anfangshöhe dem Carbolsäurezusatz 0 entspricht, so sinkt sie zunächst rasch bis nahezu auf die Abscisse, steigt dann plötzlich weit über die Anfangshöhe hinaus, um dann wieder ebenso plötzlich ganz auf die Abscisse zurückzusinken, welche sie nicht mehr verlässt. Anders ausgedrückt: Kleine Mengen Carbolsäure hindern die Fermententwicklung bis zu einem gewissen Grade, grosse Mengen unterdrïcken 
sie ganz, gewisse mittlere Mengen aber steigern sie in hohem Grade, denn der Fermentgehalt der bezüglichen Wasserextracte ist weit über die Norm erhöht. Ob ich mich richtig ausdrücke, indem ich die hemmende Wirkung der Carbolsäure auf die Fermententwicklung beziehe, ob es nicht vielleicht richtiger wäre, zu sagen, die Carbolsäure hindert resp. unterdrückt nicht die Entwicklung, sondern sie zerstört das Ferment, nachdem es sich in normaler Weise entwickelt, mag dahingestellt bleiben, aber so viel scheint mir klar zu sein, dass sie dort, wo sie im entgegengesetzten, d. h. im fördernden Sinne wirkt die Entwicklung des Fermentes beeinflusst, eben weil in diesen Präparaten nach beendeter Gerinnung der Fermentgehalt des Blutes weit über die Norm erhöht gefunden wird. Dieses Resultat war ein so auffallendes, dass ich den eben beschriebenen Versuch mit derselben Blutart wiederholte, wobei ich genau zu denselben Resultaten gelangte.

Ich stellte ihn nun auch noch mit Rinderblut an, das ich direct in mehrere gemessene Mengen Carbolsäure enthaltende, graduirte Gefässe fliessen liess. Es gelang mir ziemlich genau Mischungen mit 1/2-, 1-, 11/2-, 2-, 21/2-, 3- und 5 proc. Carbolsäure herzustellen. Da die Blutabnahme im Schlachthause stattfand, war es mir unmöglich die Gerinnungszeiten zu beobachten; auch hier stellten sich von 3 proc. Carbolsäure an starke Eiweissgerinnungen ein. Nach 24stiundigem Stehen bei Zimmertemperatur wurden die Präparate behufs Darstellang der resp. Wasserextracte mit Alkohol coagulirt u.s.w.

Die Resultate der mit diesen Extracten angestellten Gerinnungsversuche waren durchaus übereinstimmend mit den beim Pferdeblute erhaltenen, nur dass hier No. 1 ( $1 / 2$ proc. Carbolsäure) schon eine sehr verlangsamte Gerinnung zeigte, während die Beschleunigung schon bei No. $3\left(1^{1 / 2}\right.$ proc. Carbolsäure) anfing, bei No. 4 (2proc. Carbolsäure) ihr Maximum erreichte (Gerinnung des "Salzplasmas" in einigen Secunden) und in No. 5 (21/2 proc. Carbolsäure) sowie in den folgenden Nummern die Gerinnung ganz ausblieb. Das Wasserextract aus der' unter normalen Bedingungen geronnenen Blutprobe wirkte in 4 .Minuten.

Tch habe schon bemerkt, dass 2 proc. Carbolsäure im Serum das Ferment völlig unwirksam mache; dasselbe gilt aber auch, wie ich mich durch besondere Versuche überzeugt habe und wie es von vornherein natürlich erscheint, von grösseren Carbolsäurezusätzen; solche sonderbare Resultate, wie beim Blutplasma erhält man also hier durchaus nicht.

Noch sonderbarer erscheinen dieselben aber, wenn man sich 
fragt, warum zerstört die Carbolsäure, nachdem sie in geeigneten Mengen zugesetzt die Fermententwicklung gesteigert hat, nicht nachträglich beim längeren Stehen das freigewordene Ferment? Die Gerinnung war ja doch längst beendet, sogar mit beschleunigter Geschwindigkeit beendet, das Blut mithin längst serös geworden, als ich dasselbe (10 resp. 24 Stunden nach dem Aderlass) mit Alkohol coagulirte.

Es würde nun die Frage sich aufdrängen, ob aus diesen Thatsachen für die Praxis irgend eine Folgerung gezogen werden kann. Ich beschränke mich in dieser Hinsicht auf die Andeutung, dass in ihnen eine Aufforderung enthalten zu sein scheint, beim Gebrauch der Carbolsäure zu berïcksichtigen, ob dieselbe auf frisches, unmittelbar aus den Gefässen auf die Wundfläche hervortretendes also noch nicht geronnenes Blut trifft, oder auf solches, welches bereits längere Zeit in der Wunde stagnirt hat und demnach auch schon mehr weniger vollkommen geronnen, $d$. h. serös, resp. fermenthaltig geworden ist. Während nun im letzteren Falle, wo es sich um bereits vorhandenes freies Ferment handelt, dasselbe schon durch kleine Mengen Carbolsäure auf ein Minimum reducirt, durch grössere Mengen sicher zerstört wird, gibt es im ersteren Falle gewisse mittlere Carbolsäuremengen, durch welche der Fermentgehalt des Blutes gerade ausserordentlich gesteigert wird, so dass man auf einen entgegengesetzten Erfolg nur bei Ânwendung verhältnissmässig grosser Carbolsäuremengen zu rechnen hätte, Mengen, welche andererseits vielleicht unangenehme Complicationen, z. B. Ekzeme u. s. w. hervorrufen dürften.

Ich hatte eine grosse Quantität Rinderblutserum mit 1 proc. Carbolsäure versetzt und nach 24 Stunden mit Alkohol gefällt. Das getrocknete und zu Pulver zerriebene Coagulum benutzte ich zur Darstellung von Wasserextracten, mit welchen, als ihres Fermentgehalts beraubten Flussigkeiten, ich Injectionsversuche anstellte, welche, wie früher die Wasserinjectionen, zum Vergleich mit meinen Fibrinfermentinjectionen dienen sollten.

Die nachfolgenden Tabellen ergaben, dass auch hier unter 5 Versuchen dreimal das eine Fermentinjection begleitende Symptomenbild auftrat, während in den übrigen zwei Fällen die Injectionen überhaupt gar keine wahrnehmbaren. Wirkungen hervorriefen. In dem einen der drei ersterwähnten Fälle wurden dem Thiere deshalb gleichfalls von Zeit zu Zeit kleine Blutproben entzogen und direct in Alkohol aufgefangen.

Die in schon früher erwähnter Weise angestellte Untersuchung: 
dieser Blutproben ergab, dass auch hier unmittelbar nach der Injection eines fermentf reien Serumextracts Fibrinferment in beträchtlicher Menge im Blute aufgetreten und dann wieder allmählich daraus verschwunden war.

Woher stammte aber dieses Ferment? Etwa aus den Bestandtheilen des Blutes selbst, in Folge einer durch das fermentfreie Wasserextract (resp. eines seiner Bestandtheile) gesetzten Störung im Blute, welche in einzelnen Fällen, wenn das Thier im Augenblicke gerade über eine geringere Widerstandskraft disponirt, zu Stande kommt, in anderen aber nicht? Oder erscheint es erlaubter anzunehmen, dass auch hier trotz der Carbolsäure das im Blute anftretende Fibrinferment der Injectionsflüssigkeit angehört, insofern vielleicht diese Säure zwar das im Serum enthaltene freie Ferment zerstört hatte, nicht aber das Zymogen, welches möglicherweise neben dem Ferment im Serum präexistirt und in das bezuigliche Wasserextract des Coagulums übergegangen war?

Ich lasse nun die Tabellen der hierhergehörigen Versuche folgen. Die in Anwendung gezogene Lösung bezeichne ich als Lösung $D$.

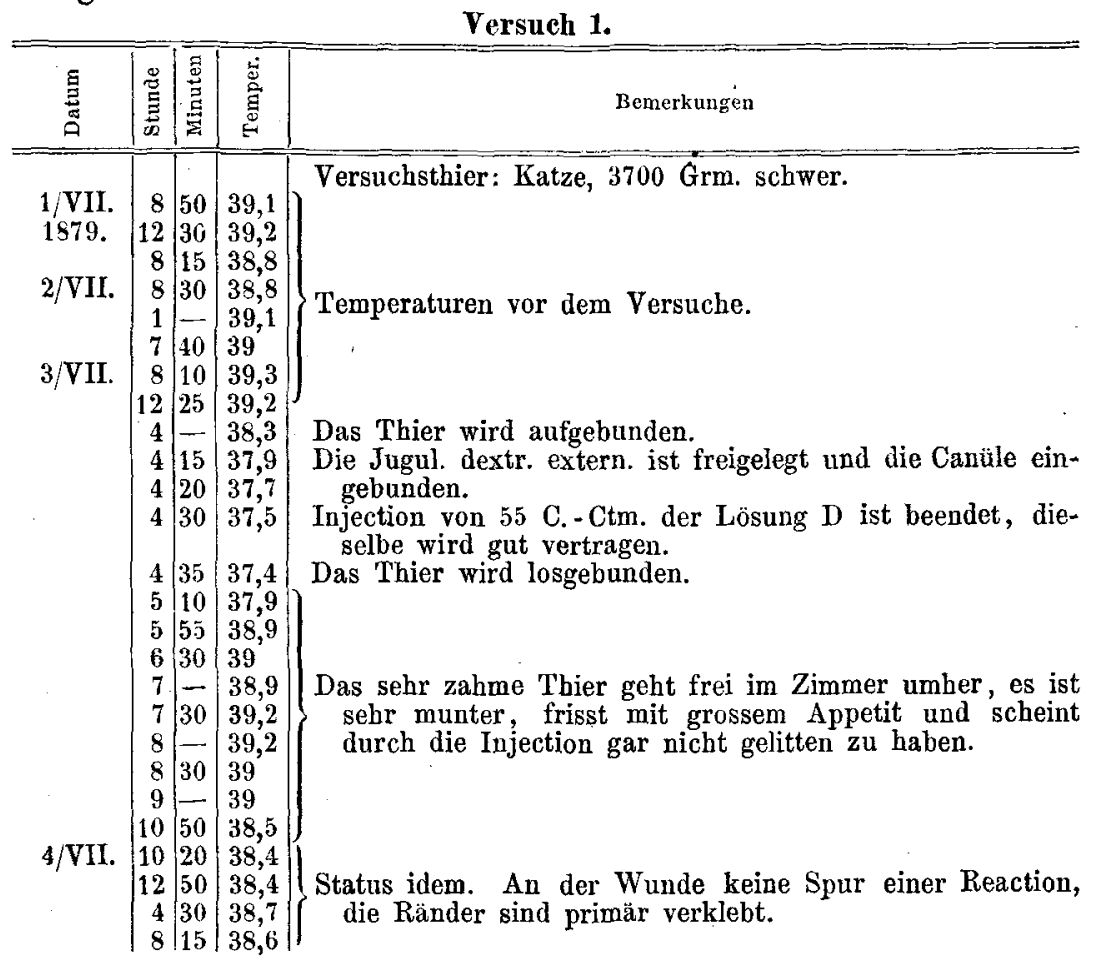




\begin{tabular}{|c|c|c|c|c|}
\hline 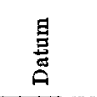 & 要 & 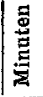 & 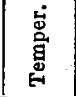 & Bemerkungen \\
\hline $\begin{array}{l}5 / \text { VII. } \\
1879 .\end{array}$ & $\begin{array}{r}8 \\
12 \\
4 \\
8\end{array}$ & $\begin{array}{l}15 \\
30 \\
40\end{array}$ & $\begin{array}{l}38,7 \\
39 \\
38,7 \\
39\end{array}$ & Status idem. Die weitere Beobachtung wird aufgegeben. \\
\hline
\end{tabular}

\section{Versuch 2.}

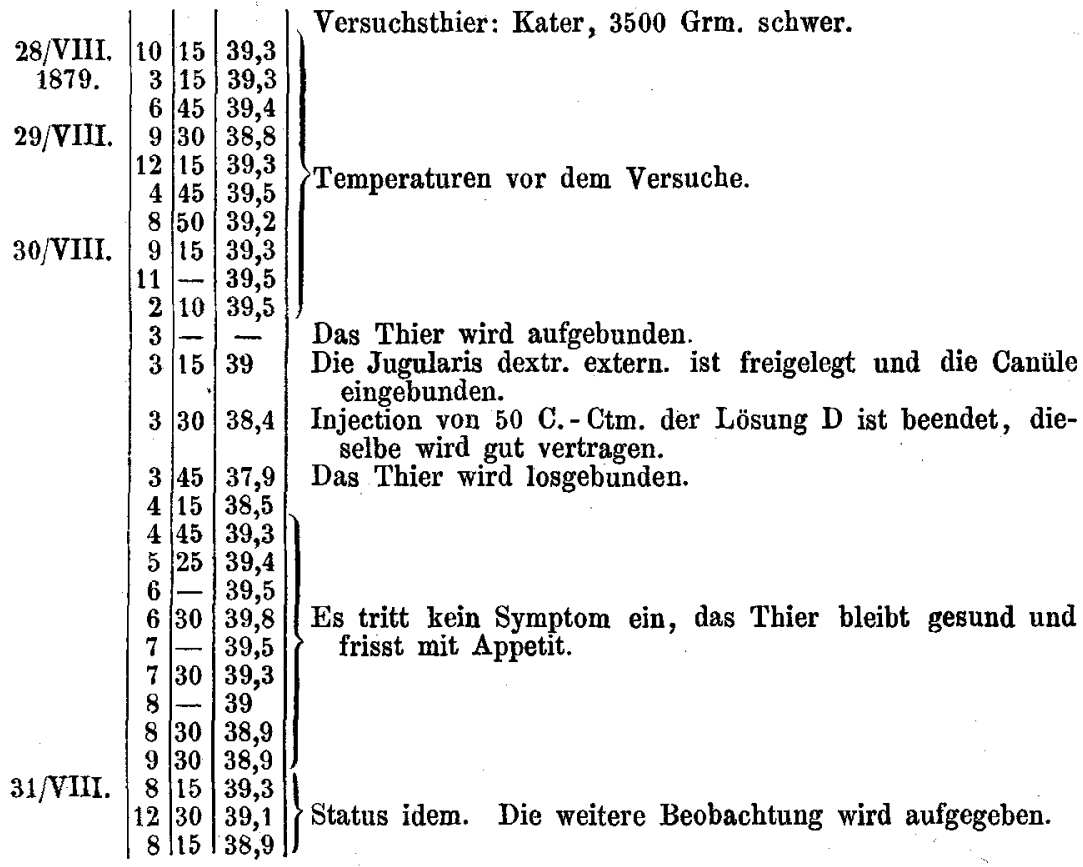

Versuch 3.

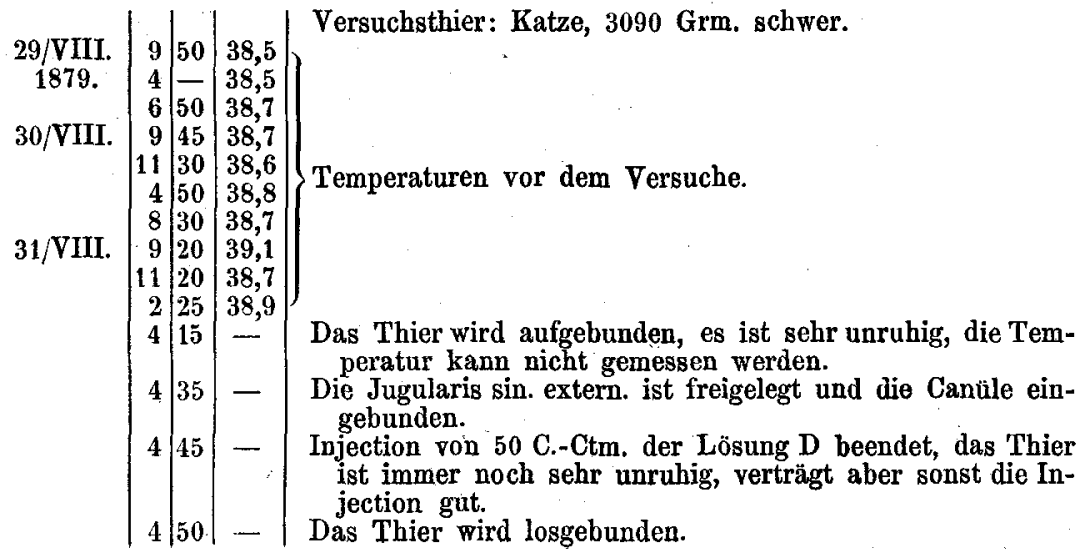


Ein Beitrag zur Lehre von der Thrombosis und vom Fieber.

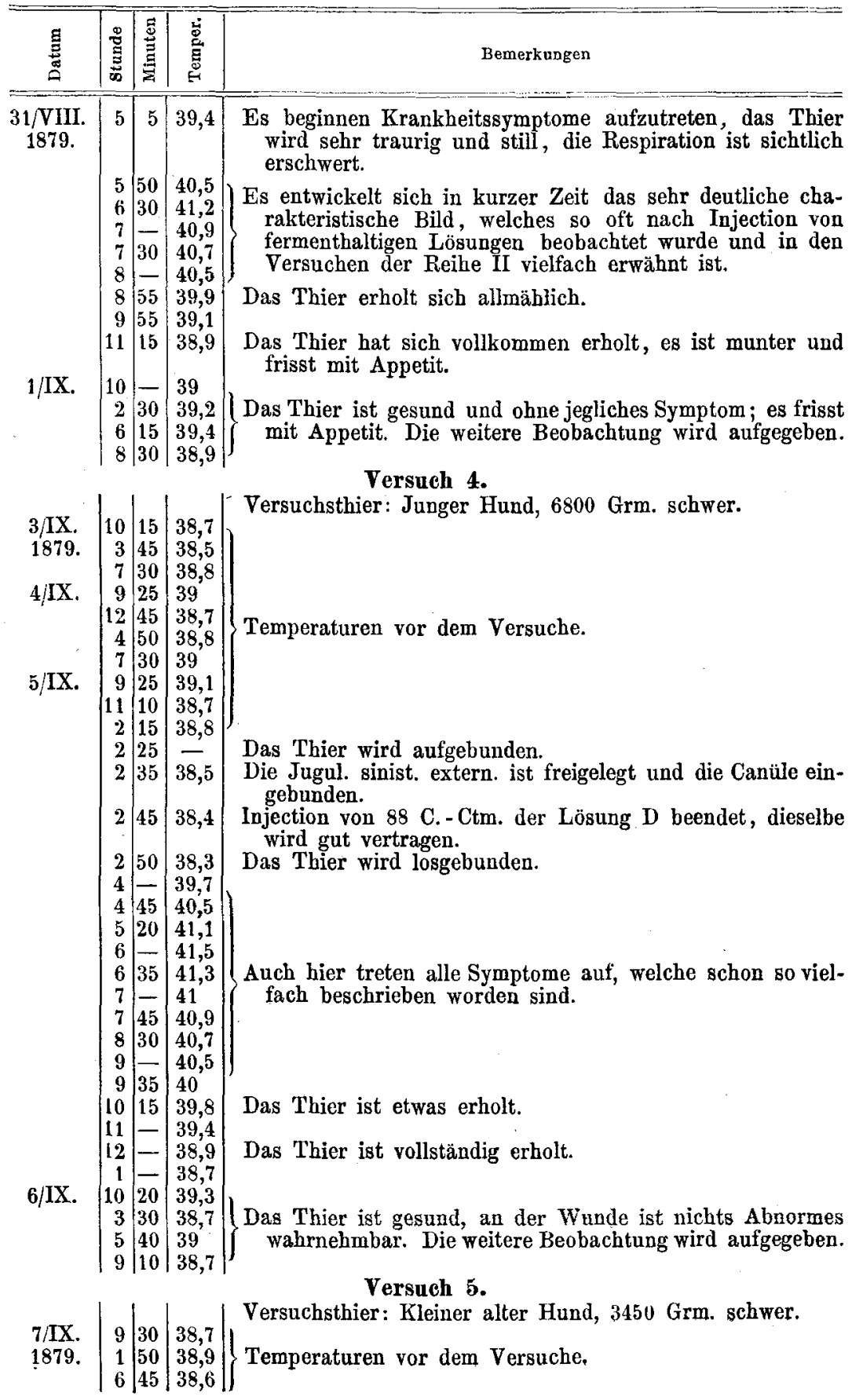




\begin{tabular}{|c|c|c|c|c|}
\hline 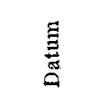 & 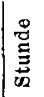 & 焉 & 完 & Bemerkungen \\
\hline \multirow{6}{*}{$\begin{array}{c}8 / \mathrm{X} . \\
1879 . \\
9 / \mathrm{X} .\end{array}$} & 10 & 25 & 39,2 & \\
\hline & 3 & 15 & 39,4 & \\
\hline & & & 38,7 & \\
\hline & 9 & 40 & 38,6 & \\
\hline & $\begin{array}{l}2 \\
6\end{array}$ & 10 & $\begin{array}{l}38,9 \\
38,5\end{array}$ & Temperaturen vor dem Versuche. \\
\hline & 8 & $\begin{array}{l}40 \\
15\end{array}$ & 38,7 & $\because$ \\
\hline \multirow[t]{17}{*}{$10 / X$} & 9 & 50 & 39,1 & , \\
\hline & 12 & 30 & 33,5 & \\
\hline & $\begin{array}{l}3 \\
3\end{array}$ & $\begin{array}{r}25 \\
30\end{array} \mid$ & 39,1 & Das Thier wird aufgebunden. \\
\hline & 3 & 45 & 38,9 & $\begin{array}{l}\text { Die Jugul. dextr. extern. wird freigelegt, aus derselben eine } \\
\text { geringe Quantität Blut direct in Alkohol aufgefangen, dann } \\
\text { wird die Canüle zur Injection eingebunden. }\end{array}$ \\
\hline & 4 & - & 38,5 & $\begin{array}{l}\text { Injection von } 45 \text { C.-Ctm. der Lösung } D \text { beendet, dann wird } \\
\text { das centrale Ende der Vene unterbunden und aus dem } \\
\text { peripheren wieder etwa } 15 \text { C.-Ctm. Blut entzogen. }\end{array}$ \\
\hline & 4 & 15 & 38,4 & $\begin{array}{l}\text { Das Thier wird losgebunden. Es beginnt sofort zu zittern } \\
\text { und sehr schnell sind alle Symptome ausgebildet. }\end{array}$ \\
\hline & 4 & 30 & 39,9 & \\
\hline & 5 & - & 40 & \\
\hline & 5 & 30 & 40,5 & Status idem. \\
\hline & $\begin{array}{l}6 \\
6\end{array}$ & $\overrightarrow{30}$ & $\begin{array}{l}40,5 \\
40,3\end{array}$ & Blutabnanme. \\
\hline & 7 & $\ldots$ & 40 & \\
\hline & 7 & 30 & 39,8 & Das Thier hat sich etwas erholt. \\
\hline & 8 & - & 39,6 & \\
\hline & 8 & 30 & 39,4 & Blutabnahme. \\
\hline & $\begin{array}{l}9 \\
9\end{array}$ & $\overline{30}$ & $\begin{array}{l}39 \\
39\end{array}$ & \\
\hline & 10 & - & 38,9 & Das Thier ist vollstăndig erholt und frisst mit Appetit. \\
\hline & 10 & 30 & 38,7 & 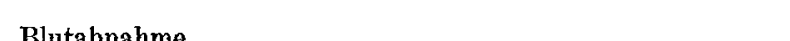 \\
\hline \multirow{3}{*}{$11 / \mathrm{X}$} & $\begin{array}{r}10 \\
9\end{array}$ & $\begin{array}{l}45 \\
30\end{array}$ & $\overline{37.7}$ & $\begin{array}{l}\text { Blutaonanme. } \\
\text { Das Thier ist gesund, der Appetit gut. }\end{array}$ \\
\hline & 1 & 40 & - & $\begin{array}{l}\text { Blutabnahme, das periphere Ende der Vene wird unter- } \\
\text { bunden, die Wunde gereinigt und ein Verband angelegt. }\end{array}$ \\
\hline & $\begin{array}{l}1 \\
5 \\
8\end{array}$ & $\begin{array}{l}15 \\
30 \\
10\end{array} \mid$ & \begin{tabular}{|l|}
38,5 \\
38,8 \\
38,3
\end{tabular} & $\begin{array}{l}\text { An dem Thier ist nichts Abnormes wahrnehmbar. Die } \\
\text { weitere Beobachtung wird aufgegeben. }\end{array}$ \\
\hline
\end{tabular}

Aus den vorstehenden Versuchen geht nun hervor, dass die Injection eines Wasserextracts, welches aus einem mit Carbolsäure behandelten Serumcoagulum erhalten worden ist, dasselbe Symptomenbild hervorrufen $\mathbf{k a n n}$, wie es so charakteristisch bei Injectionen von Fermentlösungen auftritt. Diese Symptome können aber durchaus nicht auf möglicherweise trotz der Carbolsäureeinwirkung noch erhaltene und mitinjicirte Spuren von freiem Ferment bezogen werden, denn dazu bedarf es ja eben, wie ich durch meine Versuche bewiesen zu haben glaube, der Injection sehr grosser Fermentmengen. Nur weil Jakowicki und Köhler viel fermentärmere Lösungen zu ihren Versuchen benutzten, indem sie den Gerinnungsversuch im 
Reagensglase als Maassstab für die Wirksamkeit ihrer Lösungen ansahen, konnten sie zur Annahme kommen, dass durch Injection von Fibrinferment in das Blut weder eine Temperatursteigerung, noch irgend ein anderes Symptom herbeigeführt werde. Die Wasserextracte, welche in dieser letzten Versuchsreihe von mir injicirt wurden, waren aber so fermentarm, dass sie selbst im Reagensglase kaum wahrnehmbar wirkten, sie waren also jedenfalls, wenn auch reicher an festen Bestandtheilen so doch fermentativ weit unwirksamer als die Jakowicki'schen und Köhler'schen Injectionsflüssigkeiten und wirkten im Organismus doch.

Ich bedauere nochmals, dass es mir nicht vergönnt gewesen ist, das Blut mit Bezugnahme auf das etwaige Vorkommen von Fibrinferment nach Einbringung verschiedenartiger, fiebererregender Stoffe $\mathrm{zu}$ untersuchen. Ist nicht vielleicht freies Fibrinferment im Blute eine Erscheinung, welche jede Störung im Gleichgewichtszustande des Blutes begleitet und kennzeichnet, mag die Ursache dieser Störung sein welche sie wolle? Und reagirt der Organismus gegen solche Störungen nicht vielleicht durch denjenigen Symptomencomplex, den wir Fieber nennen? Namentlich wäre das Studium der Wirkung des Wassers in dieser Hinsicht von Interesse gewesen. Sollte es sich zeigen, dass auch das Wasser eine mit Fermententwicklung verbundene Störung im Blute zu erzeugen im Stande wäre, so würde es uns ganz selbstverständlich erscheinen, dass eine wässrige concentrirte Fermentlösung direct in das Blut gebracht eine viel grössere Schädlichkeit darstellt, als reines Wasser. Aber andererseits dürften wir cum grano salis auch sagen, dass auch das Glas Wasser, welches wir zur Stillung des Durstes trinken, eine Störung im Blute bewirkt, welche der Organismus wieder auszugleichen hat. Der Skeptiker darf mit einem gewissen Rechte behaupten: Alles kann Fieber, resp. Temperatursteigerung machen und der Pathologe findet nicht mehr die Grenzen zwischen seiner Domaine und der des Physiologen.

Der Organismus gebietet aber offenbar über unberechenbare, grossartige, regulatorische Vorrichtungen zur Bekämpfung der auf ihn eindringenden Schädlichkeiten, er wird alle Mittel aufbieten, sich derselben zu entledigen und hierbei unter Umständen eine grosse Arbeit leisten, welche ihren Ausdruck in einer uns messbaren Temperatursteigerung finden kann. Wird nun aber die Schädlichkeit nicht auf einmal in grösserer Quantität eingeführt, sondern dauernd, so wird der Organismus durch sein Bestreben dieselbe zu eliminiren in beständiger Arbeit erhalten, es wird beständig Wärme frei 
werden und sich uns das Phänomen darstellen, welches wir „Fieber" nennen. Anders aber wird sich die Sache gestalten, wenn die Schädlichkeit so plötzlich und in solcher Quantität dem Organismus zugeführt wird, dass ihm von vornherein jede Möglichkeit genommen wird dagegen etwas zu thun; es werden dann alle Functionen so plötzlich, so mit einem Schlage lahmgelegt werden, dass die nothwendige Folge der Tod sein muss.

Offenbar ist die Fähigkeit des Organismus, der durch das von aussen in den Körper gebrachte oder in ihm spontan entstandene Fibrinferment dargestellten Schädlichkeit Widerstand zu leisten und sie zu überwinden, individuell und vielleicht auch nach den Zuständen des Körpers eine sehr verschiedene. Deshalb kann man bei Injection von Fibrinfermentlösungen auch niemals mit Sicherheit voraussagen, ob der Tod die Folge sein wird, oder nur eine Temperatursteigerung mit den sie begleitenden Erscheinungen. Nicht selten wird ein Thier durch verhältnissmässig kleinere Mengen derselben Fermentlösung getödtet, von welcher verhältnissmässig grössere Mengen in einem anderen Thiere nur eine Temperatursteigerung bewirken.

Sind diese Vorstellungen aber richtige, so drängen sie zur weiteren Frage, ob der pathologische Zustand des Fiebers nicht stets mit dem Auftreten von nachweisbaren Mengen von freiem Fibrinferment im Blute verkntupft ist. Zur Entscheidung dieser Frage war es nur nöthig geringe Mengen Blut von Fieberkranken in Alkohol aufzufangen, dann wie gewöhnlich zu verfahren und die Wirksamkeit der Wasserextracte auf meine Reactionsflissigkeit zu prifen. Ich habe nur zwei solcher Versuche aufzuweisen und zwar an Wundfieberkranken, aber die Resultate fielen überaus günstig aus, insofern das Wasserextract rom ersten Falle (Resection des Hüftgelenks) bei gewöhnlichen Mischungsverhältnissen in 10 Minuten wirkte, während das vom zweiten Falle (Amputation des Daumens), entsprechend der geringeren Verletzung, eine halbe Stunde zur Herbeiführung der Gerinnung bedurfte. Ich füge hinzu, dass ich mich vorher mehrfach davon überzeugt hatte, dass auch das gesunde menschliche Blut durchaus nnwirksame Wasserextracte liefert, also fermentfrei ist. An einem anderen Orte komme ich ausführlicher auf diese Versuche zurtick.

Fassen wir aber nun nach allen diesen Erörterungen die Ergebnisse meiner Untersuchungen über das Fibrinferment zusammen, so können wir darüber Folgendes sagen:

1. ${ }_{n}$ Das Fibrinferment kann, in gehöriger Concentration in die ${ }_{n}$ Blutbahn gebracht, durch plötzliche Gerinnung des in den lebenden 
nGefässen circulirenden Blutes momentan den Tod hervorrufen; dass „aber nur durch die Gerinnung des Blutes der Tod hervorgerufen ist "und durch nichts anderes, dafür sprechen klar und deutlich die Sec"tionsbefunde. “

2. nIst aber die Fermentlösung entweder weniger concentrirt, oder naber sind die Verhältnisse im Organismus derartige, dass sie densel"ben befähigen energischeren Widerstand zu leisten, als unter anderen ${ }_{n}$ Umstänđen, so tritt zwar nicht der Tod ein, aber es entwickelt sich nunter sehr bedeutender Temperatursteigerung ein Symptomencomplex, n welcher ungemein charakteristisch ist für die Wirkung des Ferments. "

3. DDie ganze Reihe der Symptome wird aber auch hervorgerufen „durch Injection von aus Blut gewonnenen Wasserextracten, welche er$n$ wiesener Maassen kein freies Ferment enthalten."

4. „In solchen Fällen von Temperatursteigerung aber, ebenso auch nbeim Wundfieber, findet sich freies Fibrinferment im circulirenden Blute. "

5. „Der erwähnte Symptomencomplex sowohl als auch der Tod, ${ }_{n}$ welcher als Folge der Injection anftritt, lassen sich aber durchaus "nicht auf den Gehalt der Fermentlösungen an festen Bestandtheilen "(Eiweiss, Salze) beziehen, denn die rothen Lösungen, welche bedeu"tend weniger feste Bestandtheile hatten, wirkten, wie man sich erninnern wird, ebenso verderblich wie die verhältnissmässig bedeutend n mehr fester Bestandtheile enthaltenden farblosen Lösungen, welche, wenn ${ }_{n}$ sie kein oder nur sehr wenig Ferment enthielten, niemals tödtlich, "häufig auch nicht einmal das Wohlbefinden störend wirkten."

6. "Die Wirksamkeit einer Fermentlösung auf "Salzplasma " im ${ }_{n}$ Reagensglase kann durchaus nicht als absoluter Maassstab ihrer Wirk"samkeit im Organismus angenommen werden."

„Eine Wasserinjection ins Blut kann unter Umständen Temperantursteigerungen herbeiführen, aber dieselben sind in ihrem ganzen Ver"laufe, ihrer Höhe und ihrer Dauer von den durch eine Fermentin"jection bedingten Temperatursteigerungen durchaus verschieden."

Ich glaube nun meine Untersuchungen nicht schliessen zu dürfen, ohne einer Arbeit zu erwähnen, welche, vor kurzer Zeit erschienen, die Ergebnisse ähnlicher Untersuchungen 'enthält - ich meine die Arbeit von Angerer ${ }^{1}$ ), welche mir zu Gesicht kam, als bereits ein grosser Theil der vorliegenden Untersuchungen beendet war und meine Resultate schon feststanden. Ich hatte bereits die beiden wichtigsten Eigenschaften des Fibrinferments constatirt, dass dasselbe nämlich im Stande ist durch momentane Gerinnung den Tod herbeizufuhren, oder aber, wo das nicht der Fall ist, einen specifischen Symptomencomplex verbunden mit bedeutenden Temperatursteigerungen hervorzurufen. Angerer gebrauchte zu seinen Versuchen defibrinirtes Blut, oder, wie er es nennt, "Fermentblut" und bestätigt durch dieselben die Köhler'schen Versuche, findet jedoch

1) Klinische und experimentelle Untersuchungen über die Resorption von Blutextravasaten. Würzburg 1879. 
im Gegensatz zu denselben, dass sein Fermentblut, in den Organismus gebracht, te mperaturerhöhend wirkt. Seine Arbeit konnte somit meine Untersuchungen ebenso wenig oder ebenso viel, wie die Köhler'sche, beeinflussen, denn zwischen ihren Untersuchungen und den meinigen besteht der Unterschied, dass sie Beide das ganze Blut benutzt haben, ich aber nur den wirksamen Bestandtheil desselben in Anwendung zog, d. h. das Fibrinferment.

Schliesslich glaube ich darauf hinweisen $\mathrm{zu}$ dürfen, dass der Nachweis, dass durch eine klare, filtrirte, wässrige Flüssigkeit, deren specifische Bestandtheile aus dem Blute selbst stammen, im :Organismus die ausgedehntesten Thrombosirungen hervorgerufen werden können, nicht ohne Einfluss auf die Lehre von der Thrombose und Embolie sein dürfte.

Dorpat, den 12/24. December 1879.

\section{N A C H T R A. G.}

Ich glaube an das Vorstehende noch die Mittheilung eines Versuches anschliessen zu müssen, den ich nach beendeter Redaction meiner Arbeit angestellt habe. Es handelte sich für mich darum, zu ermitteln, ob nicht vielleicht die von mir beobachteten Temperatursteigerungen der Reihe II als Folgen anzusehen seien von ausgebreiteten durch das injicirte Fibrinferment bewirkten capillaren Thrombosirungen im Gebiete der Pulmonalis. Ich habe daher einem Hunde, um ähnliche Verstopfungen zu bewirken, eine Oelinjection in eine kleine Vene des Fusses gemacht, beobachtete aber als unmittelbare Wirkung derselben, wie nachfolgende Tabelle zeigt, nicht nur keine Temperatursteigerung, sondern im Gegentheil sogar eine beträchtliche Temperaturerniedrigung. Ich bemerke hierzu, dass die Injection nicht erfolglos blieb, da das Thier Symptome schwererer Erkrankung zeigte; es athmete äusserst frequent und erschwert, hustete sehr heftig, es lag regungslos auf der Seite; am folgenden Tage traten heftige tonische Krämpfe auf, mit deren Aufhören das Thier sich allmählich erholte.

Ich lasse nun die Tabelle selbst folgen:

\begin{tabular}{|c|c|c|c|c|}
\hline 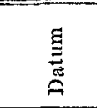 & 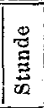 & 总 & 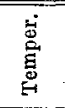 & Bemerkungen \\
\hline & & & & $\begin{array}{l}\text { Versuchsthier: Mittelgrosser, kräftiger Hund, } 11085 \text { Grm. } \\
\text { schwer. }\end{array}$ \\
\hline 13/XII. & 10 & 30 & 39 & \\
\hline & $\begin{array}{l}3 \\
7\end{array}$ & $\begin{array}{l}15 \\
30\end{array}$ & $\begin{array}{l}39,5 \\
39,3\end{array}$ & Temperaturen vor dem Versuche. \\
\hline $14 / \mathrm{XII}$. & 9 & 30 & 39,2 & \\
\hline
\end{tabular}


Ein Beitrag zur Lehre von der Thrombosis und vom Fieber.

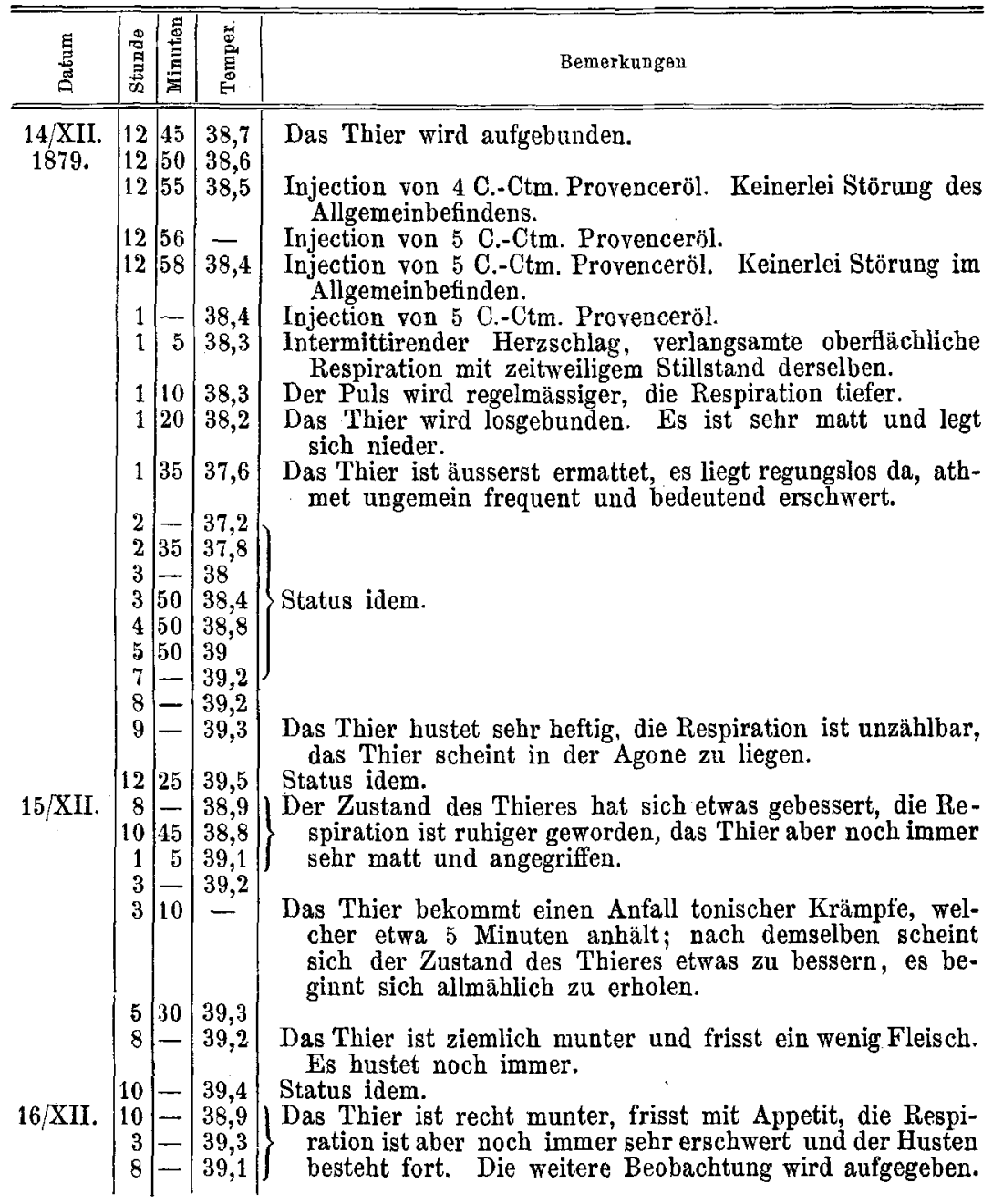

